\title{
Combine and conquer: manganese
} synergizing anti-TGF- $\beta$ /PD-L1 bispecific antibody YM101 to overcome immunotherapy resistance in non-inflamed cancers

\author{
Ming Yi ${ }^{1}$, Mengke Niu' ${ }^{1}$ Jing Zhang ${ }^{2}$, Shiyu Li ${ }^{1}$, Shuangli Zhu' ${ }^{1}$, Yongxiang Yan ${ }^{2}$, Ning Li ${ }^{3}$, Pengfei Zhou ${ }^{2}$,
} Qian $\mathrm{Chu}^{1}$ and Kongming $\mathrm{Wu}^{1,3^{*}}$ (1)

\begin{abstract}
Background: Our previous work showed that the anti-TGF-B/PD-L1 bispecific antibody YM101 effectively overcame anti-PD-L1 resistance in immune-excluded tumor models. However, in immune-desert models, the efficacy of YM101 was limited. Bivalent manganese $\left(\mathrm{Mn}^{2+}\right)$ is identified as a natural stimulator of interferon genes (STING) agonist, which might enhance cancer antigen presentation and improve the therapeutic effect of YM101.

Methods: The effect of $\mathrm{Mn}^{2+}$ on STING pathway was validated by western blotting and enzyme-linked immunosorbent assay. Dendritic cell (DC) maturation was measured by flow cytometry. The synergistic effect between $\mathrm{Mn}^{2+}$ and YM101 in vitro was determined by one-way mixed lymphocyte reaction, CFSE dilution assay, and cytokine detection. The in vivo antitumor effect of $\mathrm{Mn}^{2+}$ plus YM101 therapy was assessed in CT26, EMT-6, H22, and B16 tumor models. Flow cytometry, RNA-seq, and immunofluorescent staining were adopted to investigate the alterations in the tumor microenvironment.

Results: $\mathrm{Mn}^{2+}$ could activate STING pathway and promote the maturation of human and murine DC. The results of one-way mixed lymphocyte reaction showed that $\mathrm{Mn}^{2+}$ synergized YM101 in T cell activation. Moreover, in multiple syngeneic murine tumor models, $\mathrm{Mn}^{2+}$ plus YM101 therapy exhibited a durable antitumor effect and prolonged the survival of tumor-bearing mice. Relative to YM101 monotherapy and $\mathrm{Mn}^{2+}$ plus anti-PD-L1 therapy, Mn ${ }^{2+}$ plus YM101 treatment had a more powerful antitumor effect and a broader antitumor spectrum. Mechanistically, $\mathrm{Mn}^{2+}$ plus YM101 strategy simultaneously regulated multiple components in the antitumor immunity and drove the shift from immune-excluded or immune-desert to immune-inflamed tumors. The investigation in the TME indicated $\mathrm{Mn}^{2+}$ plus YM101 strategy activated innate and adaptive immunity, enhanced cancer antigen presentation, and upregulated the density and function of tumor-infiltrating lymphocytes. This normalized TME and reinvigorated antitumor immunity contributed to the superior antitumor effect of the combination therapy.
\end{abstract}

\footnotetext{
*Correspondence: wukm_lab@163.com

${ }^{1}$ Department of Oncology, Tongji Hospital of Tongji Medical College,

Huazhong University of Science and Technology, 1095 Jiefang Avenue, Wuhan 430030, People's Republic of China

Full list of author information is available at the end of the article
}

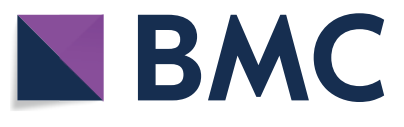

(c) The Author(s) 2021. Open Access This article is licensed under a Creative Commons Attribution 4.0 International License, which permits use, sharing, adaptation, distribution and reproduction in any medium or format, as long as you give appropriate credit to the original author(s) and the source, provide a link to the Creative Commons licence, and indicate if changes were made. The images or other third party material in this article are included in the article's Creative Commons licence, unless indicated otherwise in a credit line to the material. If material is not included in the article's Creative Commons licence and your intended use is not permitted by statutory regulation or exceeds the permitted use, you will need to obtain permission directly from the copyright holder. To view a copy of this licence, visit http://creativecommons.org/licenses/by/4.0/. The Creative Commons Public Domain Dedication waiver (http://creativeco mmons.org/publicdomain/zero/1.0/) applies to the data made available in this article, unless otherwise stated in a credit line to the data. 
Conclusion: Combining $\mathrm{Mn}^{2+}$ with YM101 has a synergistic antitumor effect, effectively controlling tumor growth and prolonging the survival of tumor-bearing mice. This novel cocktail strategy has the potential to be a universal regimen for inflamed and non-inflamed tumors.

Keywords: The tumor microenvironment, Manganese, cGAS-STING, PD-L1, TGF- $\beta$, Bispecific antibody, Cancer immunotherapy

\section{Background}

For a robust antitumor immune response, a sequence of stepwise events should be appropriately initiated, proceeded, and propagated [1]. This cyclic process starts with antigen release and ends with tumor-killing by immune cells $[2,3]$. Ideally, the immune system could recognize all malignantly transformed cells and inhibit tumorigenesis [4]. However, in some situations, the antitumor immune response is hampered by negative regulators [5-8]. As a result, malignantly transformed cells escape from immune clearance and develop into overt tumors [9].

Programmed cell death protein 1/programmed cell death ligand 1 (PD-1/PD-L1) is a vital immune checkpoint signal in maintaining immune homeostasis [10]. In the tumor microenvironment (TME), the PD-1/PD-L1 axis is commonly hijacked by cancer cells to restrain the activities of tumor-infiltrating lymphocytes (TILs) [11, 12]. Blocking the PD-1/PD-L1 axis restores $\mathrm{T}$ cells from exhausted status and reinitiates a self-sustaining antitumor immune response [13]. At present, anti-PD-1/PD-L1 antibodies ( $\alpha$-PD-1/PD-L1 Abs) have been successfully used to treat multiple types of cancers [14-21]. Although $\alpha-P D-1 / P D-L 1$ strategies mobilize a durable and potent antitumor immunity in some cancer patients, most patients could not benefit from this therapy [22, 23]. For these patients, PD-1/PD-L1 is not the primary speedlimiting factor for antitumor immunity, and it is insufficient to normalize the dysregulated antitumor immune response by blocking the PD-1/PD-L1 axis [24].

TGF- $\beta$ has a substantial influence on the immune system: inhibiting the proliferation and functions of $\mathrm{T}$ cells, inducing the differentiation of naïve $\mathrm{T}$ cells toward regulatory $\mathrm{T}$ cells, undermining the antigen presentation capability of dendritic cells (DCs), enhancing the functions of cancer-associated fibroblasts (CAFs), and impairing the activities of natural killer cells (NKs) [25]. Hyperactive TGF- $\beta$ signal shapes an immunosuppressive microenvironment and contributes to $\alpha$-PD-1/PD-L1 resistance [26]. Given the synergistic effect between TGF- $\beta$ and PD-1/PD-L1 in promoting immune evasion, we developed the anti-TGF- $\beta$ /PD-L1 bispecific antibody $(\alpha-T G F-\beta /$ PD-L1 BsAb) YM101 [27]. Our previous study showed that the antitumor effect of YM101 was significantly superior to that of $\alpha$-PD-L1 in some high TGF- $\beta$ tumor models [27]. However, like $\alpha$-PD-1/PD-L1, YM101 had modest antitumor effects in poorly immunogenic tumor models.

The weakly immunogenic tumors are regarded as cold tumors or immune-desert tumors [5]. In this context, inadequate cancer antigen presentation and rare cancerspecific $\mathrm{CD}^{+} \mathrm{T}$ cells in the TME lead to the primary resistance to $\alpha-\mathrm{PD}-1 / \mathrm{PD}-\mathrm{L} 1$ [16]. Enhancing the functions of antigen presentation cells (APCs) promotes the generation of cancer-specific $\mathrm{CD} 8^{+} \mathrm{T}$ cells, which might relieve the primary resistance to $\alpha$-PD-1/PD-L1 [28]. Recently, some studies indicated that an innate immune signal, stimulator of interferon genes (STING), might be a valuable target for cancer immunotherapy [29]. As the downstream production of STING pathway, type I interferon (IFN-I) promotes the maturation and function of DCs and strengthens the cytotoxicity of effector cells [30]. It has been verified that STING agonist could synergize $\alpha$-PD-1/PD-L1 in cancer immunotherapy [31]. Even in poorly immunogenic tumor models such as B16, STING agonist combined with $\alpha-P D-1 / P D-L 1$ therapy significantly prolonged survival of mice, relative to corresponding monotherapies [32]. Bivalent manganese $\left(\mathrm{Mn}^{2+}\right)$ is identified as a natural STING agonist [33-35]. In a phase I clinical study, $\mathrm{Mn}^{2+}$ plus $\alpha-\mathrm{PD}-1$ treatment had an enhanced antitumor effect and manageable safety profile [36].

Hereto, we supposed that the cocktail strategy containing $\mathrm{Mn}^{2+}$ and YM101 would have a broader antitumor spectrum and better therapeutic efficacy by simultaneously boosting innate and adaptive immunity and overcoming multiple immunosuppressive factors. In this work, we explored the synergistic effect between $\mathrm{Mn}^{2+}$ and YM101 in T cell activation assays in vitro. Besides, we investigated the antitumor effect of $\mathrm{Mn}^{2+}$ plus YM101 in murine tumor models with high TGF- $\beta$ or low immunogenicity.

\section{Materials and methods \\ Cell lines and therapeutic Abs}

Murine cancer cell lines CT26 (colon cancer), EMT-6 (breast cancer), H22 (hepatocellular carcinoma), and B16 (melanoma) were cultured with RPMI-1640 containing $10 \%$ fetal bovine serum. The therapeutic Abs and corresponding isotype, including YM101, $\alpha$-murine PD-L1, 
$\alpha$-TGF- $\beta$, and human IgG (hIgG), were provided by Wuhan YZY Biopharma. YM101 is an $\alpha$-TGF- $\beta /$ PD-L1 $\mathrm{BsAb}$ developed based on the Check-BODY ${ }^{\mathrm{TM}}$ platform [27].

\section{Western blotting}

Protein was extracted and separated as described [37, 38]. Human-Reactive STING Pathway Antibody Sampler Kit $(38,866$, CST), Mouse-Reactive STING Pathway Antibody Sampler Kit $(16,029$, CST), and $\alpha$-GAPDH (5174, CST) were used in this assay. SuperSignal ${ }^{\mathrm{TM}}$ West Pico PLUS (34,577, Thermo Scientific) was used for signal detection.

\section{Induction of DC}

Human peripheral blood mononuclear cells (PBMCs) were obtained from healthy donors. $\mathrm{CD} 14^{+}$PBMCs were isolated from PBMCs by EasySep ${ }^{\mathrm{TM}}$ Human Monocyte Isolation Kit (19,359, Stemcell). Human monocyte-derived DCs (MoDCs) were induced from CD14 ${ }^{+}$ PBMCs by ImmunoCult ${ }^{\mathrm{TM}}$ Dendritic Cell Culture Kit $(10,985$, Stemcell) according to the recommendations of manufacturers. Briefly, $2.5 \times 10^{5} /$ well monocytes were seeded in 6-well plates and cultured with differentiation medium for three days. Later, the supernatant was removed after centrifugation and replaced with fresh differentiation medium. The plates were further cultured for 2 days, and then, $20 \mathrm{ng} / \mathrm{ml}$ Lipopolysaccharides (LPS) (L2630, Sigma-Aldrich) or $1 \mathrm{mM}$ manganese chloride (244,589, Sigma-Aldrich) was added. After incubation for 1 day, cells were collected for further flow cytometry assays. $\alpha$-CD80 (305,208, BioLegend), $\alpha$-CD86 (374,206, BioLegend), $\alpha$-HLA-DR (307,606, BioLegend), and $\alpha$-CD11c (561,355, BD Biosciences) Abs were used to measure the maturation of DCs. Moreover, PD-L1 level was also detected in the flow cytometry assays using $\alpha$-PD-L1 Ab (374,512, BioLegend).

Murine bone marrow-derived DCs (BMDCs) were induced as described [36]. The differentiation medium contained murine granulocyte-macrophage colonystimulating factor (GM-CSF) $(20 \mathrm{ng} / \mathrm{ml}, 315-03-50 \mathrm{UG}$, PeproTech) and murine IL-4 (20 ng/ml, 214-14-50UG,
PeproTech). Bone marrow cells were obtained from $\mathrm{BALB} / \mathrm{c}$ mice and seeded in tissue-culture treated $\mathrm{T}-25 \mathrm{~cm}^{2}$ flasks with differentiation medium. 2 days later, the supernatant was replaced with fresh differentiation medium, and the suspension cells were discarded. On day 5 , the supernatant was removed after centrifugation and replaced with fresh differentiation medium. Then, the cells were treated with $20 \mathrm{ng} / \mathrm{ml}$ LPS or $0.5 \mathrm{mM}$ $\mathrm{Mn}^{2+}$ for 1 day. Then, cells were harvested for flow cytometry assays. $\alpha$-CD80 (560,016, BD Biosciences), $\alpha$-CD86 (105,008, BioLegend), $\alpha$-I-A/I-E (107,608, BioLegend), $\alpha$-CD11c (553,801, BD Biosciences), and $\alpha$-PD-L1 $(124,312$, BioLegend) Abs were used in the flow cytometry assays.

\section{Enzyme-linked immunosorbent assay (ELISA) and cell viability evaluation}

Immature human MoDCs $\left(1 \times 10^{6} / \mathrm{ml}\right)$ and murine BMDCs $\left(2 \times 10^{6} / \mathrm{ml}\right)$ were treated with $\mathrm{Mn}^{2+}$ for 1 day. The supernatants were harvested for ELISA. Human and murine IFN- $\beta$ levels were measured by Human IFN-beta Quantikine ELISA Kit (DIFNB0, R\&D) and Mouse IFNbeta Quantikine ELISA Kit (MIFNB0, R\&D). The ELISAs were performed following the recommendations of manufactures. The suspension and adherent cells were collected to measure cell viability by $\mathrm{AO} / \mathrm{PI}$ double staining (CS2-0106-5ML, Nexcelom Bioscience).

\section{One-way mixed lymphocyte reaction (MLR)}

In the MLR, the simulator cells were saline-treated or $\mathrm{Mn}^{2+}$-treated murine BMDCs from BALB/c mice. The responder cells were splenocytes from $\mathrm{C} 57 \mathrm{BL} / 6$ mice. Before the MLR, the stimulator cells were treated by Mitomycin-C (40 $\mu \mathrm{g} / \mathrm{ml}$, M5353, Sigma-Aldrich) for $30 \mathrm{~min}$, and the responder cells were labeled with carboxyfluorescein diacetate succinimidyl ester (CFSE) $(5 \mu \mathrm{M}$, 65-0850-84, ThermoFisher). The ratio of responder to stimulator was $2: 1$. Then, TGF- $\beta 1$ and treatment Abs were added to the mixed cells. The mixed cells were cultured with RPMI-1640 containing 10\% fetal bovine

\footnotetext{
(See figure on next page.)

Fig. $1 \mathrm{Mn}^{2+}$ activated STING pathway and promoted dendritic cell (DC) maturation. a-c Western blotting assays and ELISAs exploring the effect of $\mathrm{Mn}^{2+}$ treatment on STING pathway in human monocyte-derived DCs (MoDCs) and murine bone marrow-derived DCs (BMDCs). After 1 mM Mn ${ }^{2+}$ or other divalent cations including $\mathrm{Ca}^{2+}$ and $\mathrm{Mg}^{2+}$ treatment for $24 \mathrm{~h}$, the levels of $\mathrm{p}-\mathrm{STING}$, STING, $\mathrm{p}-\mathrm{TBK} 1, \mathrm{TBK} 1, \mathrm{p}-\mathrm{IRF} 3$, and IFN- $\beta$ were measured. d-e The dose-dependent effect and toxicity of $\mathrm{Mn}^{2+}$ in vitro. Human MoDCs and murine BMDCs were treated with different concentrations of $\mathrm{Mn}^{2+}$ for $24 \mathrm{~h}$. The IFN- $\beta$ concentration in the supernatant was measured by ELISA, and the viability of MoDCs and BMDCs was determined by AO/

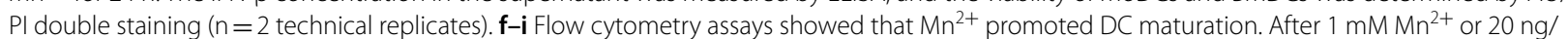
ml LPS (positive control) treatment for $24 \mathrm{~h}$, the mean fluorescence intensities (MFIs) of CD80, CD86, and HLA-DR on human MoDCs were measured. After $0.5 \mathrm{mM} \mathrm{Mn}^{2+}$ or $20 \mathrm{ng} / \mathrm{ml}$ LPS treatment for $24 \mathrm{~h}$, the MFIs of CD80, CD86, and I-A/I-E on murine BMDCs were measured $(n=3$ technical replicates). ${ }^{*} p<0.05,{ }^{* *} p<0.01,{ }^{* * *} p<0.001$, and ${ }^{* * * *} p<0.0001$ denote the significant difference relative to the last group when not marked with lines. MoDC: monocyte-derived dendritic cell; BMDC: bone marrow-derived dendritic cell; MFI: mean fluorescence intensity
} 
a

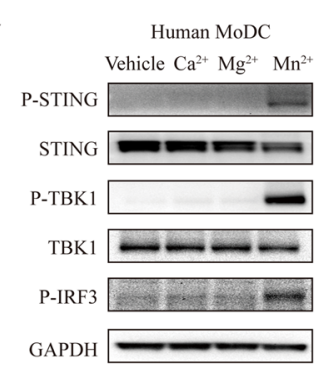

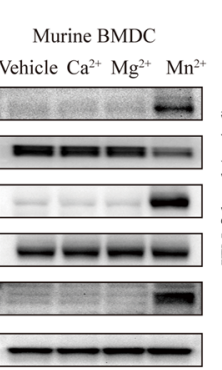

b
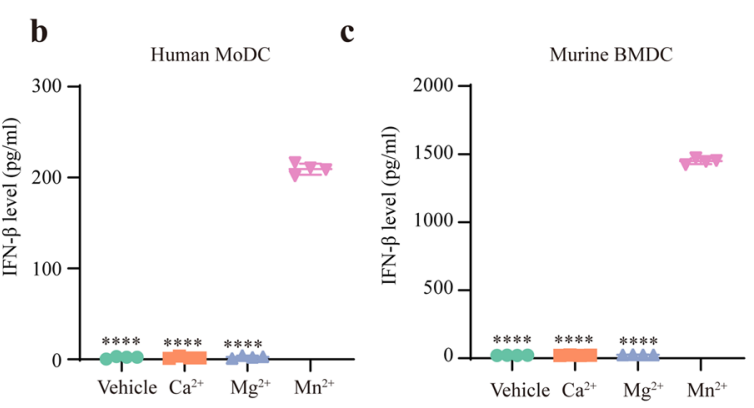

d
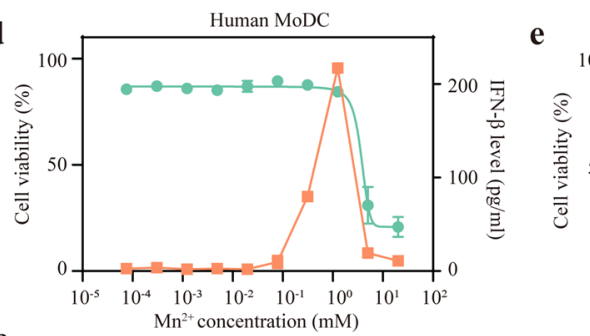

f Human MoDC
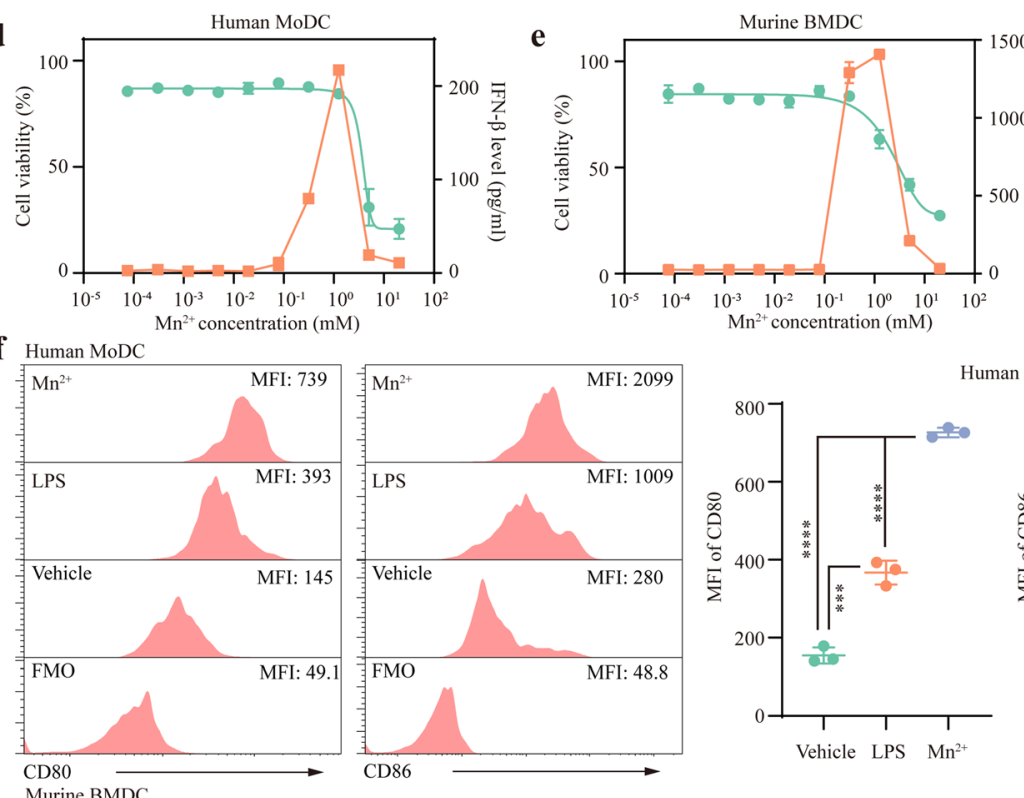

g Murine BMDC

g $\underset{\mathrm{Mn}^{2+}}{\stackrel{\text { Murin }}{\mathrm{Mn}^{2+}}}$

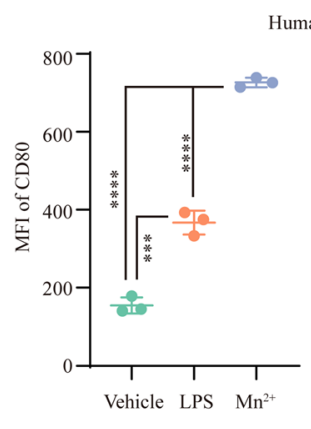

Human MoDC
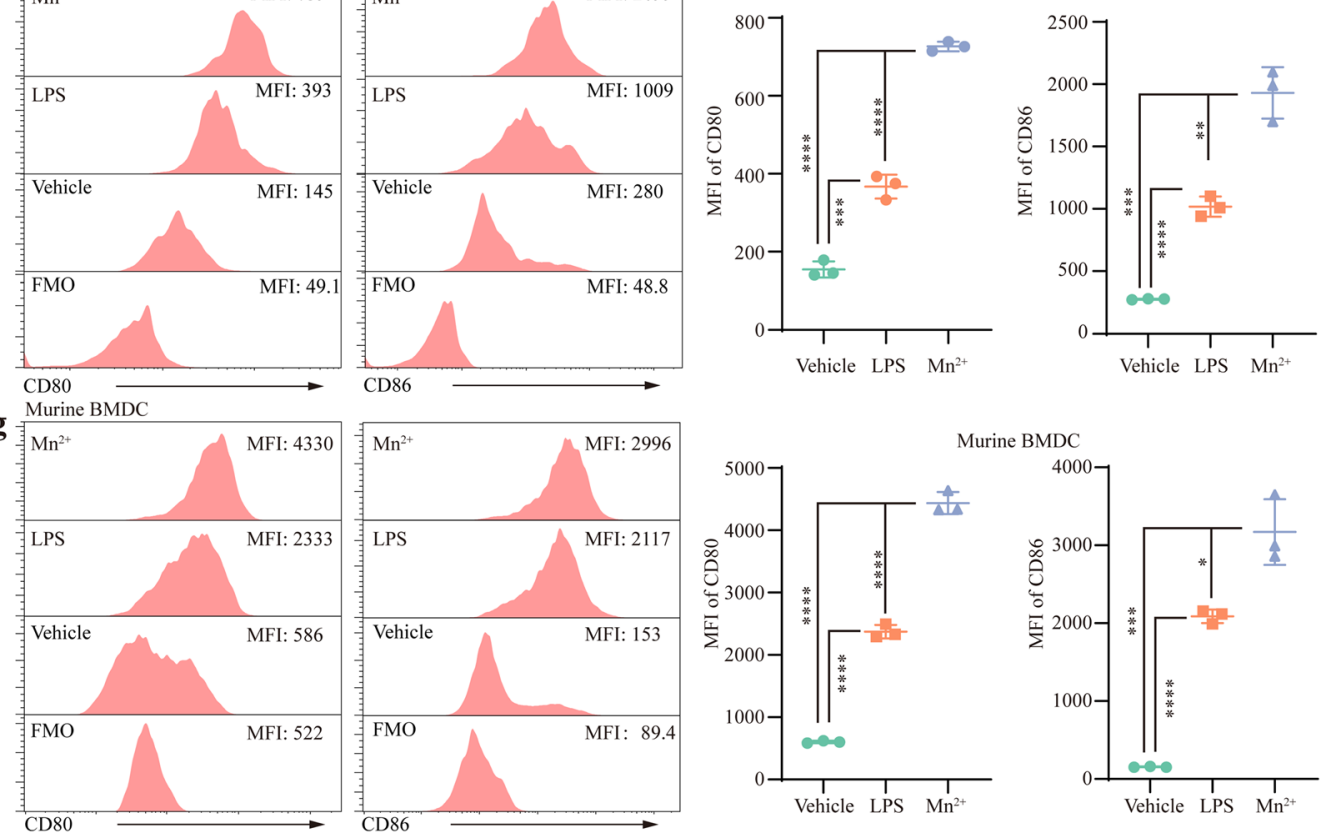

h Human MoDC
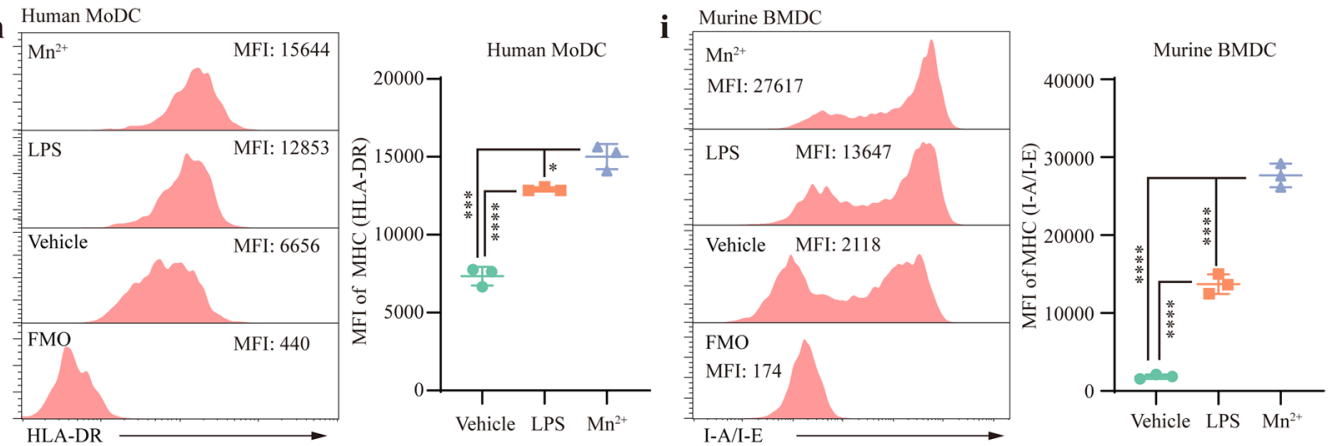

Fig. 1 (See legend on previous page.) 
serum for $96 \mathrm{~h}$. Subsequently, the mixed cells and supernatants were harvested to measure cell proliferation and cytokine levels. The ratios of daughter $\mathrm{CD} 4^{+}$and $\mathrm{CD} 8^{+}$ $T$ cells were determined by CFSE dilution assays ( $\alpha$-CD4: 100,516, BioLegend; $\alpha$-CD8 $\alpha$ : 563,068, BD Biosciences). The cytokine levels were measured by LEGENDplex ${ }^{\mathrm{TM}}$ MU Th Cytokine Panel (741,044, BioLegend).

\section{Murine tumor models}

We explored the antitumor effect of $\mathrm{Mn}^{2+}$ combined with YM101 in multiple murine tumor models, including CT26, EMT-6, H22, and B16. All mice were treated every other day for 12 days. For $\mathrm{Mn}^{2+}$ administration, mice received $5 \mathrm{mg} / \mathrm{kg} \mathrm{Mn}{ }^{2+}$ intranasally or intratumorally. For $\mathrm{Ab}$ treatment, mice were treated with equivalent mole hIgG $(6.6 \mathrm{mg} / \mathrm{kg}), \alpha$-PD-L1 $(6.6 \mathrm{mg} / \mathrm{kg})$, or YM101 $(9 \mathrm{mg} / \mathrm{kg})$ by intraperitoneal injection. Tumor growth was monitored every 2 days, and tumor volume was calculated as following: volume $=0.5 \times$ length $\times$ width $^{2}$. Mice were killed when tumor volume was over $2500 \mathrm{~mm}^{3}$ or when the experiment ended.

\section{Subcutaneous CT26 model}

$\mathrm{BALB} / \mathrm{c}$ mice were subcutaneously inoculated in the right groin with $1 \times 10^{6} \mathrm{CT} 26$ cells on day 0 . Tumor-bearing mice were randomized into six groups: Isotype control, $\mathrm{Mn}^{2+}, \alpha-\mathrm{PD}-\mathrm{L} 1, \mathrm{Mn}^{2+}$ plus $\alpha$-PD-L1, YM101, and $\mathrm{Mn}^{2+}$ plus YM101 (8 mice for each group). Treatment started on day 4 when tumor volumes reached $50 \sim 100 \mathrm{~mm}^{3}$.

\section{Orthotopic EMT-6 model}

$\mathrm{BALB} / \mathrm{c}$ mice were inoculated in the right mammary fat pad with $5 \times 10^{5}$ EMT- 6 cells on day 0 . Treatment was initiated on day 4 when tumor volumes reached $50 \mathrm{~mm}^{3}$. We then explored the effect of the combination treatment on the survival of EMT-6-bearing mice. BALB/c mice were challenged with $3 \times 10^{5}$ EMT- 6 cells on day 0 . Therapy was initiated on day 2 . The survival status of mice was monitored for 45 days.
Subsequently, we investigated the durable antitumor effect of the combination treatment. BALB/c mice were challenged with $3 \times 10^{5}$ EMT-6 cells on day 0 . Therapy was initiated on day 1 . One week after the last treatment, the untreated or cured mice were rechallenged with $3 \times 10^{5}$ EMT-6 cells.

\section{Subcutaneous $\mathrm{H} 22$ model}

$\mathrm{BALB} / \mathrm{c}$ mice were subcutaneously inoculated in the right groin with $2 \times 10^{6} \mathrm{H} 22$ cells on day 0 . Tumor-bearing mice were randomized into four groups: Isotype control, $\mathrm{Mn}^{2+}$, YM101, and $\mathrm{Mn}^{2+}$ plus YM101 (8 mice for each group). Treatment started on day 4 when tumor volumes reached $50 \mathrm{~mm}^{3}$.

\section{Subcutaneous B16 model}

Besides immune-excluded model, we also evaluated the treatment efficacy in immune-desert model. C57BL/6 mice were subcutaneously inoculated with $2 \times 10^{5}$ B16 cells on day 0 . Treatment was started on day 1 . Then, we investigated whether the combination therapy could prolong the survival of tumor-bearing mice in the weakly immunogenic tumor model. C57BL/6 mice were subcutaneously inoculated with $2 \times 10^{5}$ B16 cells on day 0 . Treatment was started on day 1 . The survival status of mice was monitored for 4 weeks.

\section{Lung metastatic B16 model}

We explored the antitumor effect of the combination therapy in the lung metastatic B16 model. C57BL/6 mice were intravenously injected with $2 \times 10^{5}$ B16 cells on day 0 . Treatment was started on day 1.21 days after inoculation, the mice were euthanized, and the lung tissues were collected for H\&E staining.

\section{Flow cytometry for tumor-infiltrating lymphocytes (TILs)}

Murine tumor tissues were scissored and digested with Collagenase B (1 mg/ml, 11,088,807,001, Roche), DNase I $(0.5 \mathrm{mg} / \mathrm{ml}$, abs47047435, Absin), and Hyaluronidase $\left(1 \mathrm{mg} / \mathrm{ml}\right.$, abs47014926, Absin) at $37^{\circ} \mathrm{C}$ for $1 \mathrm{~h}$. Then, the prepared suspensions were filtered through $40 \mu \mathrm{m}$

\footnotetext{
(See figure on next page.)

Fig. $2 \mathrm{Mn}^{2+}$ treatment upregulated PD-L1 and synergized YM101 in one-way mixed lymphocyte reaction (MLR) assay. a-b The effect of Mn ${ }^{2+}$ treatment on PD-L1 expression on dendritic cells (DCs). After $1 \mathrm{mM} \mathrm{Mn}^{2+}$ treatment for $24 \mathrm{~h}$, the mean fluorescence intensity (MFI) of PD-L1 on MoDCs was measured. After $0.5 \mathrm{mM} \mathrm{Mn}{ }^{2+}$ treatment for $24 \mathrm{~h}$, MFI of PD-L1 on BMDCs was measured ( $\mathrm{n}=3$ technical replicates). $\mathbf{c}-\mathbf{k}$ MLR assay exploring the synergistic effect between $\mathrm{Mn}^{2+}$ treatment and YM101. BMDCs from BALB/c mice were used as stimulator cells, and splenocytes from C57BL/6 mice were used as responder cells. The immature BMDCs were treated with $0.5 \mathrm{mM} \mathrm{Mn}^{2+}$ or saline for $24 \mathrm{~h}$. The ratio of responder to stimulator was 2:1. Then, TGF- $\beta 1(20 \mathrm{ng} / \mathrm{ml})$ and antibodies $\left(10^{5} \mathrm{pM}\right)$ were added to the mixed cells. After culture for $96 \mathrm{~h}$, the ratio of daughter $C D 8^{+} T$ cell and the cytokine levels in the supernatant were measured ( $n=4$ technical replicates). The ratio of daughter CD $8^{+} T$ cell by CFSE dilution assays (c) and the cytokine levels were measured by LEGENDplex ${ }^{\mathrm{TM}}$ MU Th Cytokine Panel. The cytokine levels were visualized by heatmap (d). The levels of IFN- $\gamma$, TNF- - , IL-4, IL-5, IL-6, IL-10, and IL-13 are shown $(e-k) .{ }^{*} p<0.05,{ }^{* *} p<0.01,{ }^{* * *} p<0.001$, and ${ }^{* * * *} p<0.0001$ denote the significant difference relative to the last group when not marked with lines. MoDC: monocyte-derived dendritic cell; BMDC: bone marrow-derived dendritic cell; MFI: mean fluorescence intensity; MLR: mixed lymphocyte reaction
} 
a

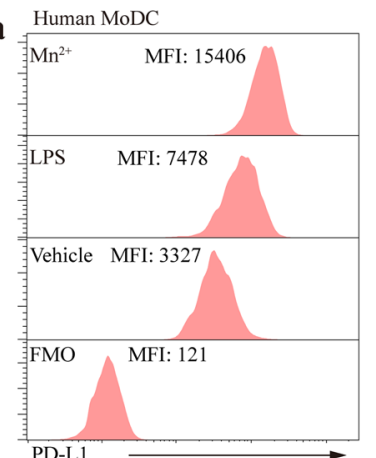

c

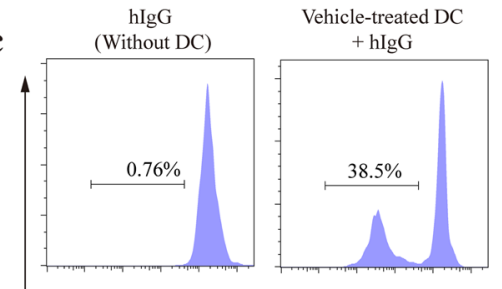

$\mathrm{Mn}^{2+}$-treated $\mathrm{DC}+$

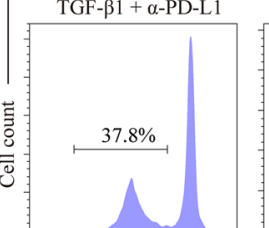

CFSE (Gated on CD8 $8^{+}$cells)

d

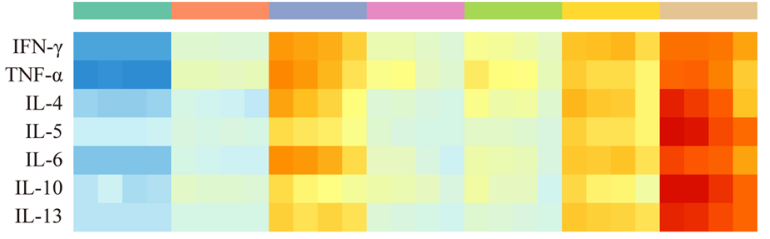

e IFN- $\gamma$

10007 TNF $-\alpha$

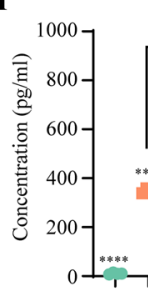

g
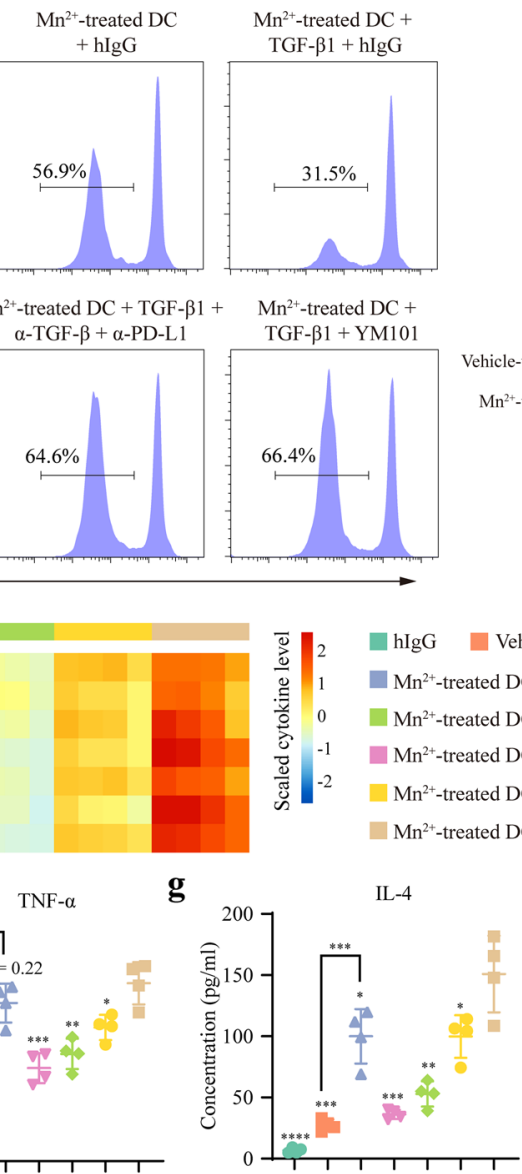

$\mathrm{Mn}^{2+}$-treated DC +

$\mathrm{Mn}^{2+}$-treated DC + TGF- $\beta 1+$

$\alpha$-TGF- $\beta+\alpha$-PD-L

$\mathrm{Mn}^{2+}$-treated DC +

TGF- $\beta 1+$ YM101

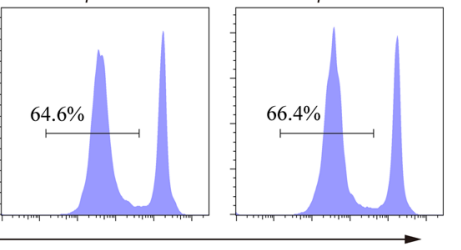

$\overline{0}-\mathrm{hIgG}$

$\mathrm{Mn}^{2+}$-treated DC + hIgG

- $\mathrm{Mn}^{2+}$-treated DC + TGF- $\beta 1+\alpha$-PD-L1

否

总 -2

$\mathrm{Mn}^{2+}$-treated DC + TGF- $\beta 1+\alpha-\mathrm{TGF}-\beta$

$\mathrm{Mn}^{2+}$-treated DC + TGF- $\beta 1+$ YM101

h
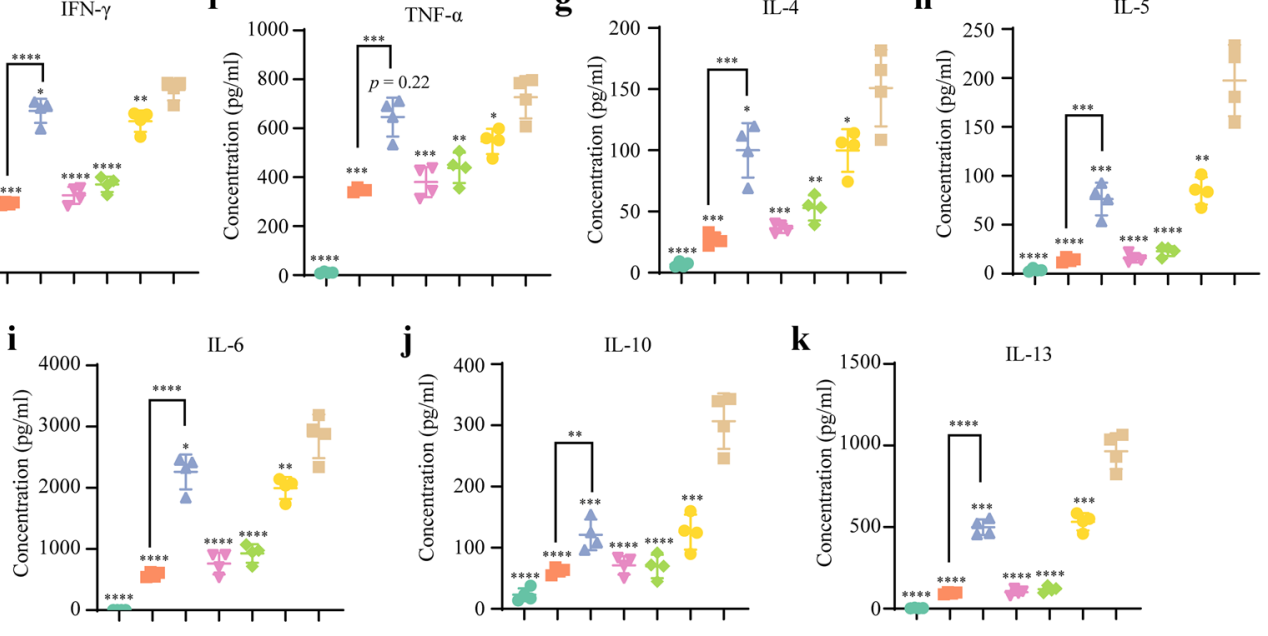

hIgG

Vehicle-treated DC + hIgG

$\mathrm{Mn}^{2+}$-treated DC $+\mathrm{TGF}-\beta 1+\alpha-\mathrm{PD}-\mathrm{L} 1$

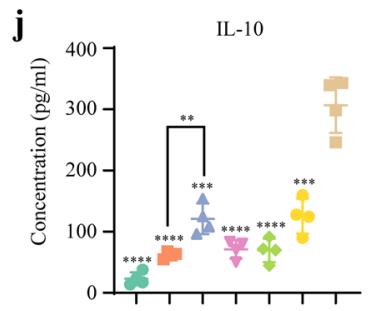

k

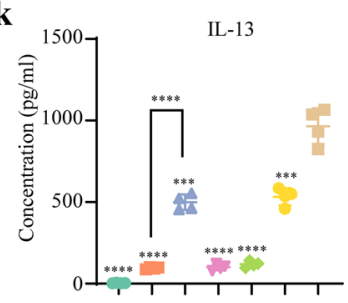

$\Delta \mathrm{Mn}^{2+}$-treated DC + hIgG $\quad \nabla \mathrm{Mn}^{2+}$-treated DC + TGF- $\beta 1+$ hIgG

$\mathrm{Mn}^{2+}$-treated DC + TGF- $\beta 1+\alpha-\mathrm{TGF}-\beta$

$\mathrm{Mn}^{2+}$-treated DC $+\mathrm{TGF}-\beta 1+$ YM101

Fig. 2 (See legend on previous page.) 
strainers (CSS013040, JET BIOFIL). Before staining, the cells were dyed with Fixable Viability Stain 780 (565,388, BD Biosciences) and blocked with Ultra-LEAF ${ }^{\mathrm{TM}}$ Purified $\alpha$-mouse $C D 16 / 32 \quad(101,339$, BioLegend). The detection Abs used in this assay were $\alpha$-CD45 $(560,510$, BD Biosciences), $\alpha$-CD3e (562,600, BD Biosciences), $\alpha$-CD8 $\alpha$ (563,068, BD Biosciences), $\alpha$-CD49b (740,363, BD Biosciences), $\alpha$-Ki67 (556,027, BD Biosciences), $\alpha$-Granzyme-B $\quad(372,204, \quad$ BioLegend $), \quad \alpha$-CD107a (564,349, BD Biosciences), $\alpha$-CD69 (566,500, BD Biosciences), $\alpha$-CD25 (553,075, BD Biosciences), $\alpha$-CD44 (561,859, BD Biosciences), $\alpha$-TNF- $\alpha$ (563,943, BD Biosciences), $\alpha$-Perforin (11-9392-82, ThermoFisher), $\alpha$-CD11c (566,504, BD Biosciences), and $\alpha-\mathrm{I}-\mathrm{A} / \mathrm{I}-\mathrm{E}$ $(107,608$, BioLegend). The auxiliary reagents used in this assay were FOXP3/Transcription Factor Staining Buffer Set (00-5523-00, ThermoFisher), Brilliant Stain Buffer (563,794, BD Biosciences), and GolgiPlug (555,029, BD Biosciences). Total cell count per $100 \mathrm{mg}$ tumor tissue was calculated with Vi-Cell Auto (Beckman Coulter). Flow cytometry was performed with BD FACSCelesta. FACS data were analyzed using Flowjo v10.

\section{Immunofluorescent (IF) staining}

Tissues were fixed with $10 \%$ formalin for $48 \mathrm{~h}$. Then, fixed tissues were dehydrated, and embedded, sectioned, and transferred to slides. Tyramide signal amplificationbased IF staining was conducted as described [39]. The Abs targeting CD3 (ab231775, Abcam), CD4 (ab183685, Abcam), CD8 (ab217344, Abcam), p-TBK1 (5483, CST), TGF- $\beta 1$ (ab215715, Abcam), $\alpha$-SMA (ab7817, Abcam), Vimentin (10,366-1-AP, Proteintech), Collagen-I (BS-10423R, Bioss) were used in this assay. Immunofluorescent images were previewed with Caseviewer software, and the regions of interest were circled by two pathologists.
The quantitative analysis of IF staining was performed with ImageJ software. The expression level of one specific protein was measured by the integral optical density of fluorescence signal. The depth of $\mathrm{T}$ cell infiltration was measured as described [27]. Briefly, the infiltration depth of one $\mathrm{T}$ cell was determined by the scaled distance of the $\mathrm{T}$ cell to the nearest tumor border. For each region of interest, the infiltration depth was calculated as the mean infiltration depth of all involved T cells.

\section{RNA-seq assay}

After six times of treatments, four samples were randomly selected from each group for RNA-seq. The reference genome was Mus_musculus.GRCm38. The mRNA was extracted by Trizol and enriched by Oligo (dT)labeled beads. The cDNA library construction, treatment with unique identifier adapter, and further deep sequencing were performed by Wuhan Seqhealth. The differentially expressed genes (DEGs) were screen out by $\mathrm{R}$ software (version: 4.0.0) with the edgeR package. The visualization of DEG profile was performed with pheatmap package. Gene Set Enrichment Analysis (GSEA) was performed using $\mathrm{R}$ with packages enrichplot and ClusterProfiler [40]. The antitumor immunity-related signatures were constructed and scored as previously reported (Additional File 1: Table S1) [27]. For the calculation of signature scores, a pseudocount of 0.001 RPKM was added to all genes. The scores of immune signatures were compared using the ROAST algorithm [41].

\section{Statistical analyses}

Statistical calculations were performed with GraphPad Prism 8. For the data with Gaussian distribution and equal variance, Student's $t$ test was adopted to compare the difference between two groups. For the data with Gaussian distribution and heteroscedasticity, Welch's

\footnotetext{
(See figure on next page.)

Fig. $3 \mathrm{Mn}^{2+}$ plus YM101 therapy had a potent and durable antitumor activity in vivo. All mice were treated every other day for 12 days. For Mn ${ }^{2+}$ administration, mice received $5 \mathrm{mg} / \mathrm{kg} \mathrm{Mn^{2+ }}$ intranasally or intratumorally. For Ab treatment, mice were treated with equivalent mole hlgG (6.6 mg/ $\mathrm{kg})$, a-PD-L1 (6.6 mg/kg), or YM101 (9 mg/kg) by intraperitoneal injection. a-c BALB/c mice were subcutaneously inoculated in the right groin with $1 \times 10^{6} \mathrm{CT} 26$ cells on day 0 . Tumor-bearing mice were randomized into six groups: Isotype control, Mn ${ }^{2+}, \mathrm{a}-\mathrm{PD}-\mathrm{L} \mathrm{1}, \mathrm{Mn}{ }^{2+}$ plus a-PD-L1, YM101, and $\mathrm{Mn}^{2+}$ plus YM101 (eight mice for each group). Treatment started on day 4. The representative images of CT26 tumors, tumor growth curves, and tumor weights are shown. $\mathbf{d}-\mathbf{f}$ BALB/c mice were inoculated in the right mammary fat pad with $5 \times 10^{5} \mathrm{EMT}-6$ cells on day 0 . Tumor-bearing mice were randomized into six groups: Isotype control, $\mathrm{Mn}^{2+}, \mathrm{a}-\mathrm{PD}-\mathrm{L} 1, \mathrm{Mn}^{2+}$ plus a-PD-L1, YM101, and Mn ${ }^{2+}$ plus YM101 (eight mice for each group). Treatment was initiated on day 4. The representative images of EMT-6 tumors, tumor growth curves, and tumor weights are shown. g-i BALB/C mice were subcutaneously inoculated in the right groin with $2 \times 10^{6} \mathrm{H} 22$ cells on day 0 . Tumor-bearing mice were randomized into four groups: Isotype control, $\mathrm{Mn}^{2+}, \mathrm{YM101}$, and $\mathrm{Mn}^{2+}$ plus YM101 (eight mice for each group). Treatment started on day 4. The representative images of H22 tumors, tumor growth curves, and tumor weights are shown. j-I C57BL/6 mice were subcutaneously inoculated with $2 \times 10^{5}$ B16 cells on day 0 . Treatment was started on day 1 (eight mice for each group). The representative images of B16 tumors, tumor growth curves, and tumor weights are shown. $(\mathbf{m})$ The schematic diagram of the rechallenge assay. BALB/c mice were inoculated with $3 \times 10^{5} \mathrm{EMT}-6$ cells in the right mammary fat pad. Therapy was initiated on day 1 . Mice received six times of treatments in 12 days. One week after the last treatment, the cured or treatment-naïve mice were rechallenged with $3 \times 10^{5}$ EMT-6 cells. (n-o) The representative images of EMT-6 tumors and tumor growth curves in the rechallenge assay are shown. ${ }^{*} p<0.05,{ }^{* *} p<0.01,{ }^{* * *} p<0.001$, and ${ }^{* * *} p<0.0001$ denote the significant difference relative to $\mathrm{Mn}^{2+}$ plus YM101 therapy when not marked with lines. CR: complete regression
} 


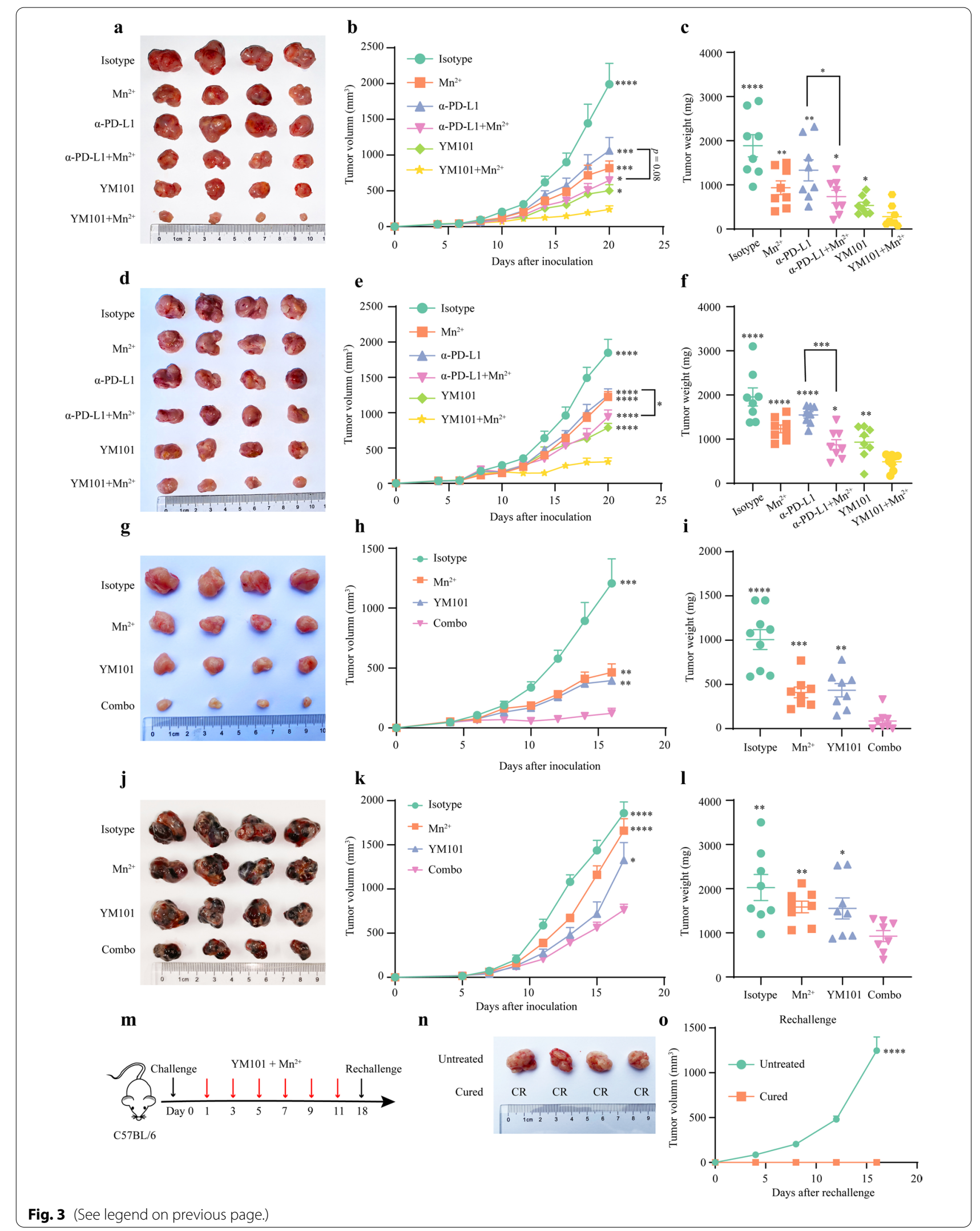




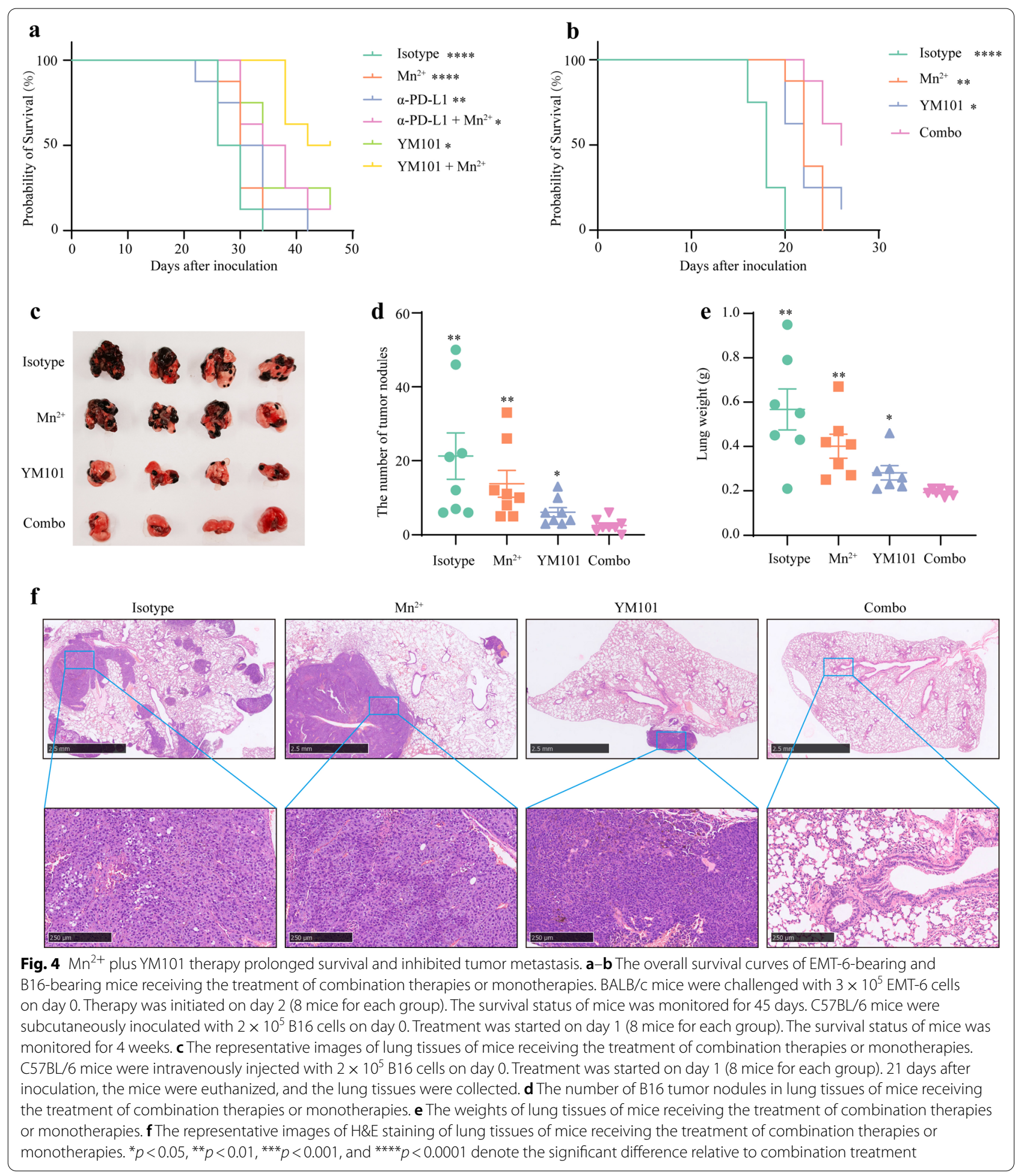


(See figure on next page.)

Fig. $5 \mathrm{Mn}^{2+}$ plus YM101 therapy promoted the transformation from immune-excluded to immune-inflamed tumors and enhanced immune cell infiltration in the EMT-6 model. a The representative flow cytometry images of tumor-infiltrating CD8 ${ }^{+} \mathrm{T}$ cells. $\mathbf{b}$ The representative flow cytometry images of tumor-infiltrating natural killer cells (NKs). c The representative images of a-CD3 staining in the tumor periphery and the tumor center. d The quantitative analysis for T cell number by integral fluorescence intensity. $\mathbf{e}$ The quantitative analysis for the depth of T cell infiltration ( $n=5$ biological replicates). ${ }^{*} p<0.05,{ }^{* *} p<0.01,{ }^{* * *} p<0.001$, and ${ }^{* * *} p<0.0001$ denote the significant difference relative to Mn ${ }^{2+}$ plus YM101 therapy

correction was adopted. For the data not coincident with normal distribution, Mann-Whitney test was used to compare the difference between two groups. All tests were two-sided, and a $p$ value below 0.05 was regarded statistically significant.

\section{Results}

\section{$\mathrm{Mn}^{2+}$ specifically activated STING pathway}

We measured the effects of multiple divalent cations, including $\mathrm{Ca}^{2+}, \mathrm{Mg}^{2+}$, and $\mathrm{Mn}^{2+}$, on STING pathway. Among these divalent cations, only $1 \mathrm{mM} \mathrm{Mn}^{2+}$ activated STING pathway in MoDCs and BMDCs: promoting the phosphorylation of STING, TBK-1, and IRF-3, inducing the degradation of STING, and increasing the level of IFN- $\beta$ (Fig. 1a-c). Then, we explored the dose-dependent effect and toxicity of $\mathrm{Mn}^{2+}$ in vitro. The gradient experiments showed that $1 \mathrm{mM}$ or $0.5-1 \mathrm{mM} \mathrm{Mn} 2+$ led to an optimal activation of STING pathway in MoDCs or BMDCs without significant cytotoxicity (Fig. 1d and e). Therefore, in the following in vitro experiments, $1 \mathrm{mM}$ or $0.5 \mathrm{mM} \mathrm{Mn}^{2+}$ was used to treat MoDCs or BMDCs.

\section{$\mathrm{Mn}^{2+}$ promoted the maturation of $\mathrm{DC}$}

Characterized by abundant co-stimulatory molecules and major histocompatibility complex (MHC), mature DCs had a stronger antigen presentation capability. To test the effect of $\mathrm{Mn}^{2+}$ on DC maturation, immature MoDCs and BMDCs were treated with $\mathrm{Mn}^{2+}$ or low-dose LPS for $24 \mathrm{~h}$. We found that $\mathrm{Mn}^{2+}$ significantly increased the expression of co-stimulatory molecules CD80 and CD86 on DCs (Fig. If and g). Moreover, $\mathrm{Mn}^{2+}$ upregulated the level of major histocompatibility complex (MHC) on DCs: increasing HLA-DR on MoDCs and I-A/I-E on BMDCs (Fig. 1h and 1i). Our results indicated that $\mathrm{Mn}^{2+}$ effectively promoted the maturation of DCs.

\section{$\mathrm{Mn}^{2+}$ synergized YM101 in T cell activation}

In parallel with increased co-stimulatory molecules and MHC, PD-L1 was also upregulated on DCs after $\mathrm{Mn}^{2+}$ treatment (Fig. 2a and b). Besides, our previous work had confirmed that TGF- $\beta$ is an inhibitory factor for T cell activation [27]. Given this, we supposed that $\mathrm{Mn}^{2+}$ might synergize YM101 in a high TGF- $\beta$ microenvironment by simultaneously enhancing antigen presentation and blocking immunosuppressive factors. Exogenous TGF$\beta 1$ was added to mimic a high TGF- $\beta$ microenvironment, and one-way MLR was utilized to mimic $\mathrm{T}$ cell activation in the TME.

In this in vitro model, we found that $\mathrm{Mn}^{2+}$-treated DCs had a greater capability to present antigen and activate $\mathrm{T}$ cells. Relative to vehicle-treated DCs, $\mathrm{Mn}^{2+}$-treated DCs had a significant advantage in promoting $\mathrm{CD}^{+} \mathrm{T}$ (Additional File 1: Figure S1) and $\mathrm{CD}^{+} \mathrm{T}$ cell (Fig. 2c) proliferation. This advantage was weakened by exogenous TGF- $\beta 1$. In the meanwhile, the TGF- $\beta 1$-impaired $\mathrm{T}$ cell proliferation was partially restored by $\alpha$-PD-L1 but almost entirely restored by $\alpha-$-TGF- $\beta$. Notably, $\alpha$-PD-L1 plus $\alpha$-TGF- $\beta$ treatment and YM101 extended this advantage. In the MLR assay, $\mathrm{CD}^{+} \mathrm{T}$ cell had a higher proliferation potential than $\mathrm{CD} 4^{+} \mathrm{T}$ cell, consistent with previous reports [42].

Then, we investigated the cytokine panel during $\mathrm{T}$ cell activation to further confirm the synergistic effect between $\mathrm{Mn}^{2+}$ and YM101. Similarly, we found that $\mathrm{Mn}^{2+}$-treated DCs had a superior capability to stimulate cytokine secretion, relatively to saline-treated DCs (Fig. 2d). Besides, the DC-stimulated cytokine secretion was hampered by exogenous TGF- $\beta 1$, and the TGF$\beta 1$-undermined cytokine secretion was reversed by $\alpha$-TGF- $\beta$. Compared to $\alpha$-TGF- $\beta$, YM101 further upregulated multiple Th1/Th 2 cytokines, including IFN- $\gamma$, TNF$\alpha$, IL-4, IL-5, IL-6, IL-10, and IL-13 (Fig. 2e-2k).

\section{The potent antitumor effect of $\mathrm{Mn}^{2+}$ plus YM101}

A previous study showed that $\mathrm{Mn}^{2+}$ synergized $\alpha-\mathrm{PD}-1 /$ PD-L1 in multiple tumor models [36]. However, given the TGF- $\beta$-induced immunosuppression and treatment resistance, it was unclear if $\mathrm{Mn}^{2+}$ plus $\alpha-\mathrm{PD}-\mathrm{L} 1$ could effectively retard tumor growth in high TGF- $\beta$ models. Theoretically, in this situation, $\mathrm{Mn}^{2+}$ combined with YM101 has a superior antitumor effect to $\mathrm{Mn}^{2+}$ plus $\alpha-\mathrm{PD}-\mathrm{L} 1$. It has been confirmed that CT26, EMT-6, and $\mathrm{H} 22$ are high TGF- $\beta$ tumor models [43-45]. We assessed the antitumor effects of $\mathrm{Mn}^{2+}, \alpha$-PD-L1, $\mathrm{Mn}^{2+}$ plus $\alpha$-PD-L1, YM101, $\mathrm{Mn}^{2+}$ plus YM101 in the CT26, EMT6 , and $\mathrm{H} 22$ models. We found $\mathrm{Mn}^{2+}$ plus YM101 had the most potent antitumor activity among all treatment strategies: significantly inhibiting tumor growth and reducing tumor burden (Fig. 3a-3i). Our results indicated that the efficacy of $\mathrm{Mn}^{2+}$ plus YM101 was better than $\mathrm{Mn}^{2+}$ plus $\alpha$-PD-L1 in high TGF- $\beta$ tumor models. We then 


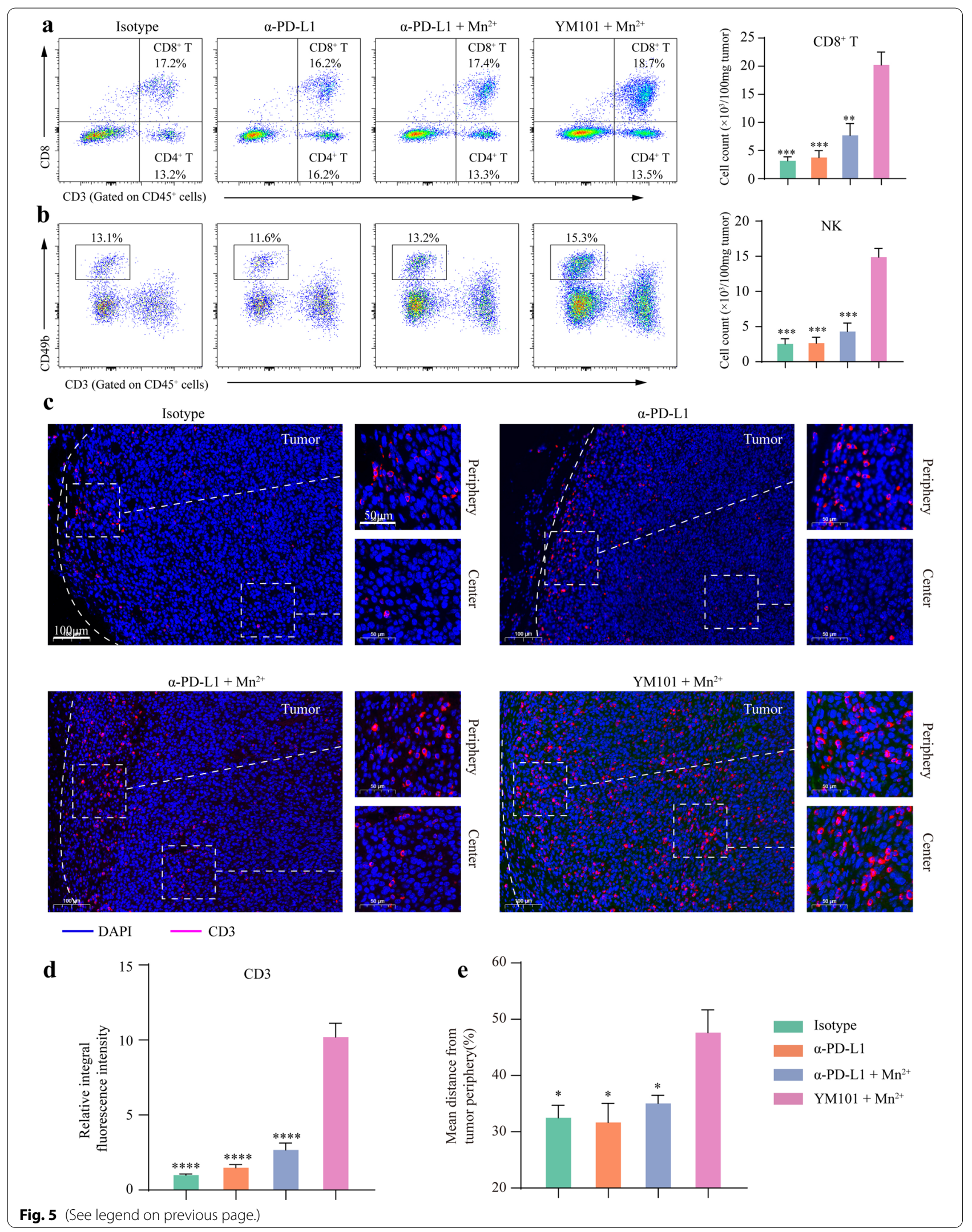


(See figure on next page.)

Fig. 6 Flow cytometry and immunofluorescent staining assays to analyze the status of $\mathrm{CD} 8^{+}$tumor-infiltrating lymphocytes (TILs) in the B16 model. The representative images of tumor-infiltrating $\mathbf{a ~ C D} 8^{+} \mathrm{T}$ cells, $\mathbf{b} \mathrm{Ki} 67^{+} \mathrm{CD} 8^{+} \mathrm{T}$ cells, $\mathbf{c}$ Granzyme- $\mathrm{B}^{+} \mathrm{CD} 8^{+} \mathrm{T}$ cells, $\mathbf{d} \mathrm{CD} 107 \mathrm{a}^{+} \mathrm{CD} 8^{+} \mathrm{T}$ cells, e CD69+ $\mathrm{CD}^{+} \mathrm{T}$ cells, $\mathbf{f} \mathrm{CD} 25^{+} \mathrm{CD} 8^{+} \mathrm{T}$ cells, and $\mathbf{g} \mathrm{CD} 44^{+} \mathrm{CD} 8^{+} \mathrm{T}$ cells in flow cytometry assays. $\mathbf{h}$ The representative images of tumor-infiltrating $\mathrm{CD}^{+}$and $\mathrm{CD} 8^{+}$T cells in immunofluorescent staining assays $\left(\mathrm{n}=5\right.$ biological replicates). ${ }^{*} p<0.05,{ }^{* *} p<0.01,{ }^{* * *} p<0.001$, and ${ }^{* * * *} p<0.0001$ denote the significant difference relative to combination treatment

investigated the antitumor effect of $\mathrm{Mn}^{2+}$ plus YM101 in the B16 model, which is regarded as a weakly immunogenic tumor model. Although YM101 exhibited a limited antitumor effect in the B16 model, $\mathrm{Mn}^{2+}$ plus YM101 significantly suppressed tumor growth (Fig. 3j-3l).

Moreover, in the EMT-6 model, we tested the durability of antitumor effect. After six times of $\mathrm{Mn}^{2+}$ plus YM101 treatments, 4 out of 8 EMT-6-bearing mice were cured. A week later, the cured mice were rechallenged with EMT-6 cells. $\mathrm{Mn}^{2+}$ plus YM101 treatment showed a potent and sustaining antitumor activity, and the tumor growth was entirely inhibited in all cured mice (Fig. 3m-3o).

Additionally, we explored the effect of $\mathrm{Mn}^{2+}$ plus YM101 treatment on the survival of tumor-bearing mice. In the EMT- 6 and B16 models, $\mathrm{Mn}^{2+}$ plus YM101 dramatically prolonged survival (Fig. $4 \mathrm{a}$ and $4 \mathrm{~b}$ ). Besides subcutaneous and orthotopic models, we also tested the antitumor effect of $\mathrm{Mn}^{2+}$ plus YM101 therapy in the lung metastatic B16 model. 21 days after intravenous injection, murine lung tissues were harvested to measure the number of tumor nodules. We found YM101 partially reduced the number of metastatic foci, while $\mathrm{Mn}^{2+}$ plus YM101 treatment almost entirely inhibited the formation of metastasis (Fig. 4c-4f).

\section{$\mathrm{Mn}^{2+}$ plus YM101 treatment shaped an immunosupportive microenvironment}

In the EMT-6 model, relative to the $\mathrm{Mn}^{2+}$ plus $\alpha$-PD-L1 group, the densities of tumor-infiltrating $\mathrm{CD}^{+}$and NK cells were significantly higher in the $\mathrm{Mn}^{2+}$ plus YM101 group (Fig. 5a and 5b). The results of IF indicated that compared to $\mathrm{Mn}^{2+}$ plus $\alpha$-PD-L1 therapy, $\mathrm{Mn}^{2+}$ plus YM101 remarkedly decreased peritumoral collagen production (Additional File 1: Figure S2) and promoted $\mathrm{T}$ cell penetration (Fig. $5 \mathrm{c}$ ). In the $\mathrm{Mn}^{2+}$ plus $\alpha$-PD-L1 group, $\mathrm{T}$ cells were primarily distributed in tumor periphery. However, in the $\mathrm{Mn}^{2+}$ plus YM101 group, the location of $\mathrm{T}$ cells was not limited in tumor periphery, but also in tumor center. $\mathrm{Mn}^{2+}$ plus YM101 treatment increased the number of tumor-infiltrating $\mathrm{T}$ cells, as well as the depth of T cell infiltration (Fig. 5d and $5 \mathrm{e}$ ). This finding was in accordance with our previous work [27]. Blocking TGF- $\beta$ signaling led to the conversion from immune-excluded to immune-inflamed tumors, providing an optimal immune cell positioning for antitumor immune response. The enhanced immune cell infiltration by $\alpha$-TGF- $\beta$ moiety might contribute to better cancer control in the $\mathrm{Mn}^{2+}$ plus YM101 group.

Then, in the B16 model, we explored the effect of $\mathrm{Mn}^{2+}$ plus YM101 on multiple components in the TME. B16 was a cold or immune-desert tumor model with rare TILs in baseline or even after YM101 treatment. However, $\mathrm{Mn}^{2+}$ plus YM101 therapy significantly upregulated the quantity and function of TILs. Flow cytometry results showed that the density of tumor-infiltrating $\mathrm{CD}^{+} \mathrm{T}$ cells was increased in the combination therapy group (Fig. 6a). Besides, the densities of Ki67 ${ }^{+}$ $\mathrm{CD}^{+}{ }^{+}$, Granzyme- $\mathrm{B}^{+} \mathrm{CD} 8^{+}$, and $\mathrm{CD} 107 \mathrm{a}^{+} \mathrm{CD} 8^{+} \mathrm{T}$ cells were markedly upregulated in the combination therapy group, indicating the higher tumor-killing capability (Fig. $6 \mathrm{~b}-6 \mathrm{~d}$ ). Moreover, the densities of activated $\mathrm{CD} 8^{+}$ $\mathrm{T}$ cell $\left(\mathrm{CD} 9^{+} \mathrm{CD} 8^{+}\right.$and $\left.\mathrm{CD} 25^{+} \mathrm{CD} 8^{+}\right)$and memory $\mathrm{CD}^{+} \mathrm{T}$ cell $\left(\mathrm{CD}_{4} 4^{+} \mathrm{CD}^{+}\right)$were increased in the $\mathrm{Mn}^{2+}$ plus YM101 group (Fig. 6e-6g). The following IF assays showed $\mathrm{Mn}^{2+}$ plus YM101 therapy promoted immune cell infiltration, converting immune-desert to immuneinflamed phenotype (Fig. 6h).

Apart from $\mathrm{CD}^{+} \mathrm{T}$ cell, NK also participates in the tumor-killing activity. We found that the density of NK $(\mathrm{CD} 3-\mathrm{CD} 49 \mathrm{~b}+)$ was highest in $\mathrm{Mn}^{2+}$ plus YM101 group (Fig. 7a). Additionally, the densities of $\mathrm{Ki}^{+} 7^{+} \mathrm{NK}$, CD107a ${ }^{+}$NK, TNF- $\alpha^{+}$NK, and Perforin ${ }^{+}$NK were markedly increased in the tumors of mice treated by $\mathrm{Mn}^{2+}$ plus YM101 (Fig. 7b-7e). Notably, the $\mathrm{Mn}^{2+}$ plus YM101 group had the highest density of DC $\left(\mathrm{CD} 11 \mathrm{c}^{+}\right.$ I-A/I-E ${ }^{+}$) (Fig. 7f). Overall, $\mathrm{Mn}^{2+}$ plus YM101 strategy effectively overcame the poor immunogenicity-caused treatment resistance and tuned an immunosupportive microenvironment.

\section{$\mathrm{Mn}^{2+}$ plus YM101 treatment promoted the gene expression related to innate immunity and adaptive immunity}

To explore the effect of the combination therapy on the expression of immunity-related genes, we performed RNA-seq assays using B16 tumor tissues (Additional File 2). Compared to Isotype, $\mathrm{Mn}^{2+}$, and YM101, $\mathrm{Mn}^{2+}$ plus YM101 group had a distinct gene expression profile. In general, the expression profile of the Isotype group was similar to that of the $\mathrm{Mn}^{2+}$ group, while the YM101 group shared a partially similar gene profile with $\mathrm{Mn}^{2+}$ plus YM101 group (Fig. 8a). The results of GSEA showed 
a
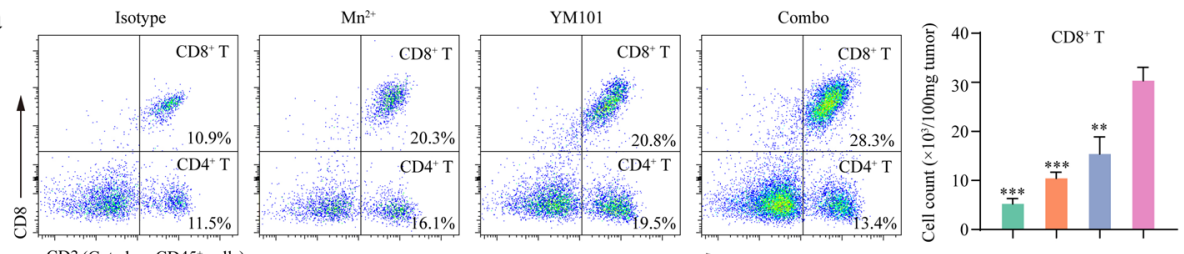

b
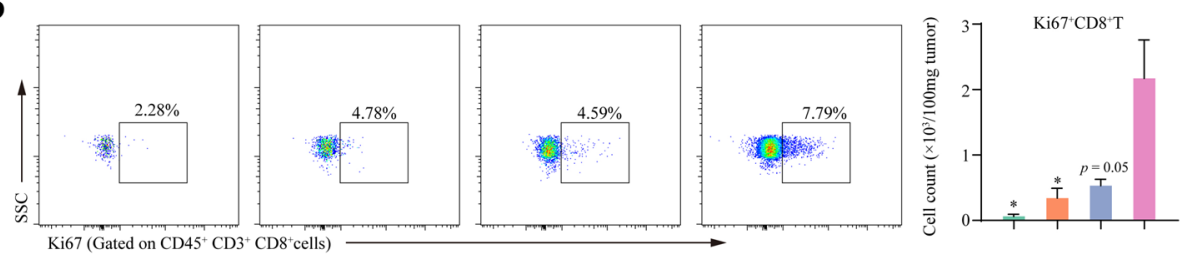

c
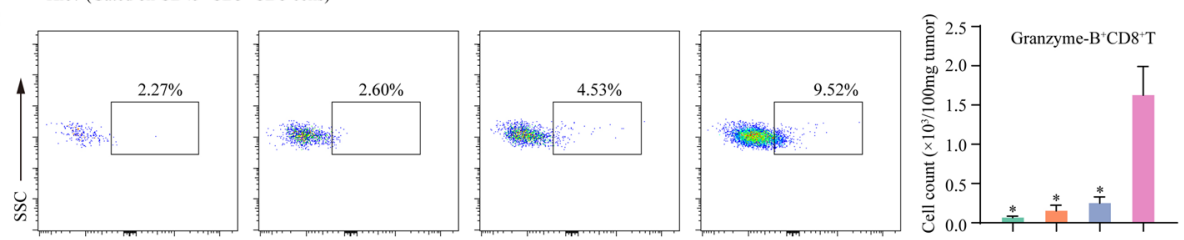

d
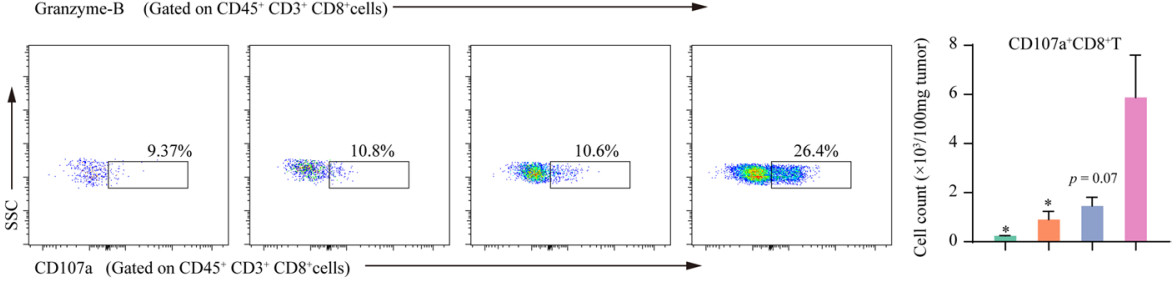

e
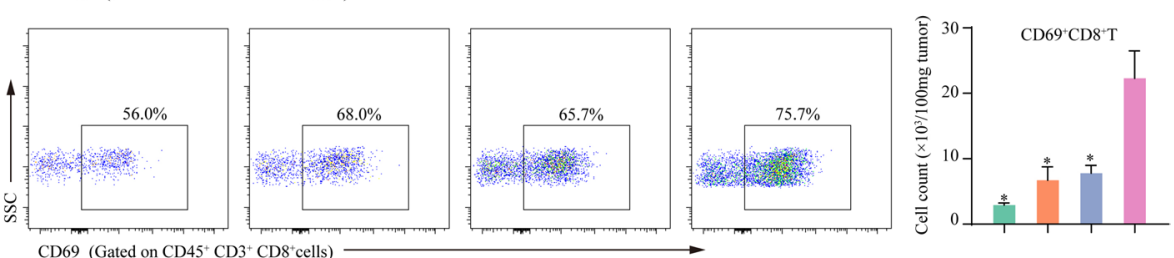

f
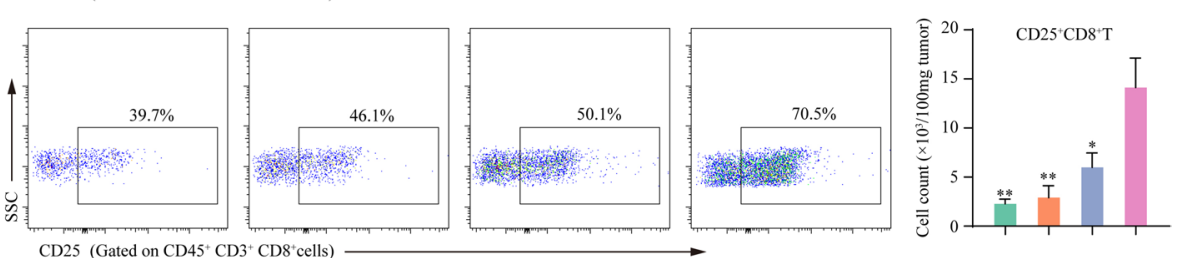

g
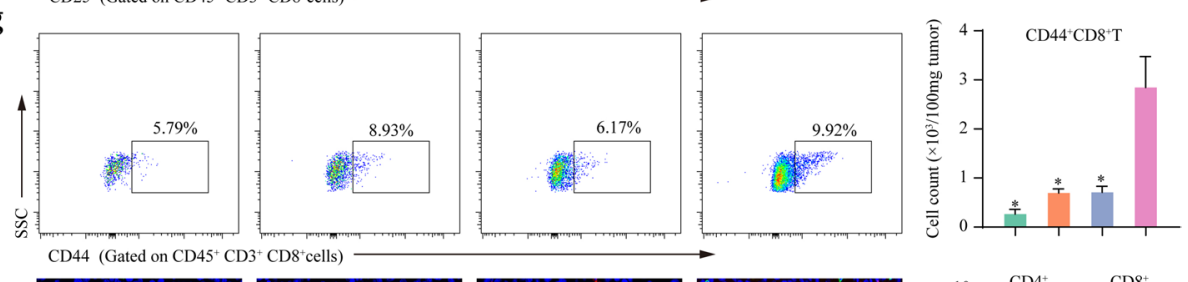

h
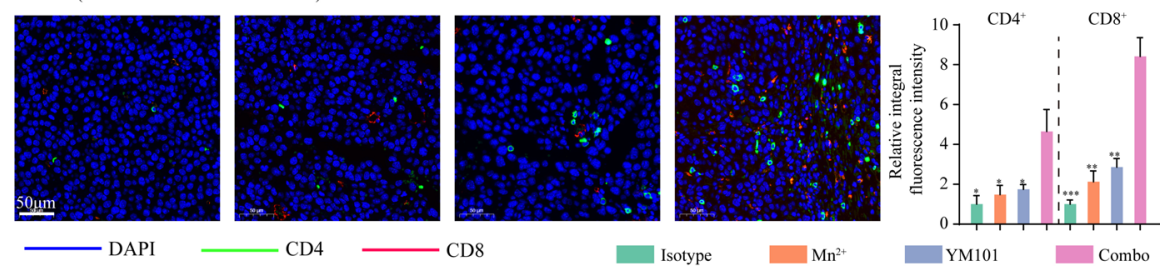

Fig. 6 (See legend on previous page.) 


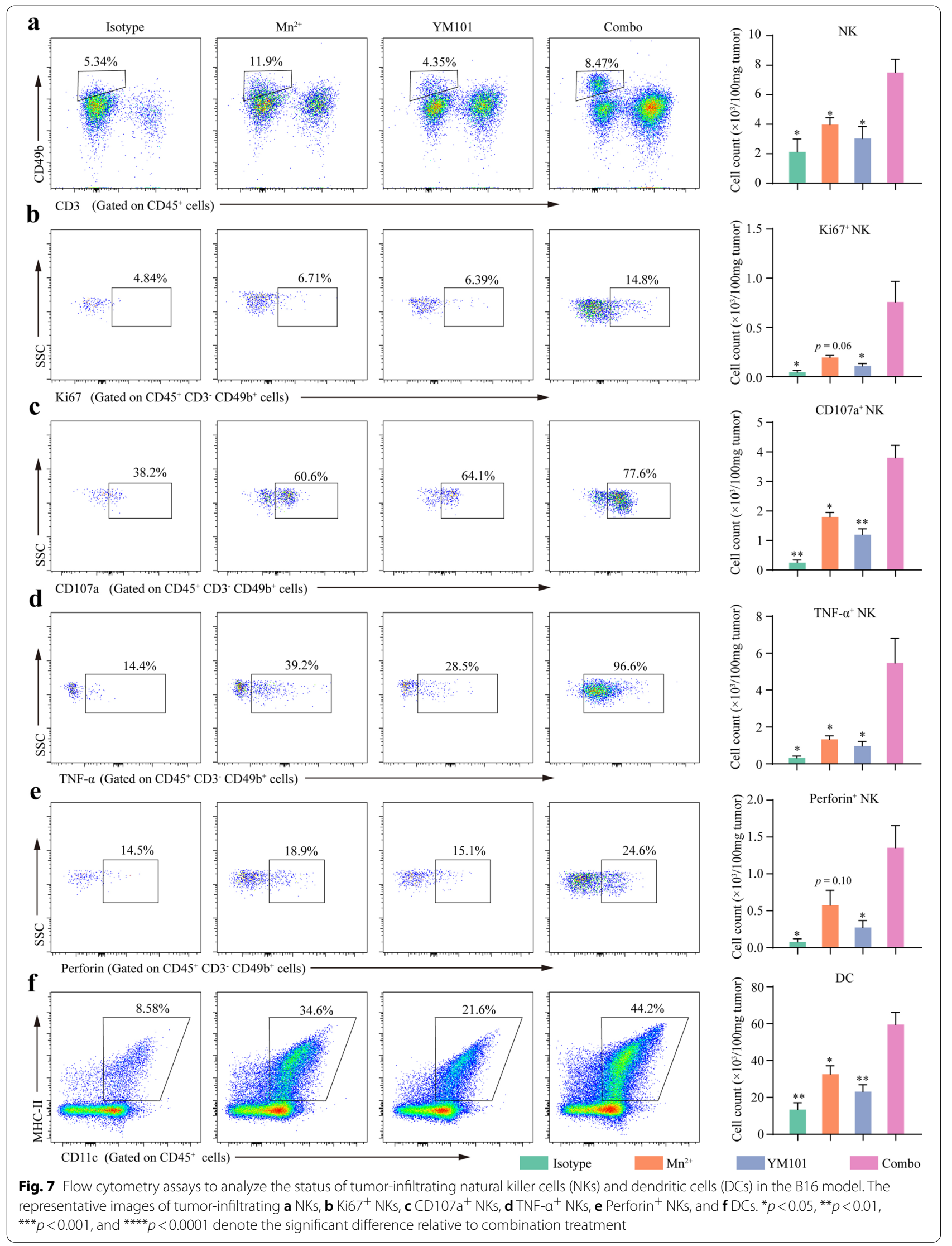


that the $\mathrm{Mn}^{2+}$ plus YM101 group had multiple significantly enriched biological processes, including activation of innate and adaptive immune response, IFN-I production and signaling pathway, activation of multiple immune cells, immune cell-mediated cytotoxicity, as well as antigen processing and presentation, relative to the YM101 group (Fig. 8b-8e).

To comprehensively assess the effect of $\mathrm{Mn}^{2+}$ plus YM101 therapy on the TME, we constructed multiple immune signatures [46]. The results showed that the scores of antitumor-associated immune signatures were highest in the $\mathrm{Mn}^{2+}$ plus YM101 group (Fig. 8f-8k). The transcriptomic data indicated that $\mathrm{Mn}^{2+}$ plus YM101 treatment had a positive effect on innate immunity and adaptive immunity, boosting multiple steps of the antitumor immune response.

\section{$\mathrm{Mn}^{2+}$ activated STING pathway and YM101 reversed epithelial mesenchymal transition (EMT) in vivo}

To validate the effect of $\mathrm{Mn}^{2+}$ on STING pathway in vivo, we performed $\alpha$-p-TBK1 IF assays. The results of IF assays showed that $\mathrm{Mn}^{2+}$ treatment activated STING pathway in the B16 model: The level of p-TBK1 was higher in the $\mathrm{Mn}^{2+}$ group and the $\mathrm{Mn}^{2+}$ plus YM101 group (Fig. 9a). $\alpha$-SMA is the marker of CAF, and Vimentin is the marker of epithelial-mesenchymal transition. The overexpression of $\alpha$-SMA and Vimentin is related to active TGF- $\beta$ signaling, which could be reversed by $\alpha$-TGF- $\beta$ moiety. Consistent with our previous work, YM101 and $\mathrm{Mn}^{2+}$ plus YM101 treatment effectively cleared the TGF- $\beta 1$ in the TME and reduced the expression of $\alpha$-SMA and Vimentin (Fig. 9b and 9c).

\section{Discussion}

According to the TME status, tumors could be divided into three phenotypes: immune-inflamed, immunedesert, and immune-excluded. Among the three phenotypes, immune-inflamed tumors are most likely to respond to $\alpha-\mathrm{PD}-1 / \mathrm{PD}-\mathrm{L} 1$ treatment. On the contrary, immune-desert and immune-excluded tumors are noninflamed tumors, which rarely respond to $\alpha$-PD-1/PD-L1 therapy. Immune-desert tumors result from immunological ignorance or lacking appropriate $\mathrm{T}$ cell priming [5].
Promoting immunogenic cancer cell death and enhancing APC's function relieve the resistance to $\alpha-P D-1 /$ PD-L1 in immune-desert tumors [28]. Immune-excluded tumors are mainly caused by abnormal vascular barriers, increased stromal collagen or fibronectin, and immunosuppressive chemokine panel [5]. Normalizing dysregulated TGF- $\beta$ signal and angiogenesis in the TME promotes the $\mathrm{T}$ cell infiltration into tumors, reverting immune-excluded to immune-inflamed tumors [47-49]. Multi-omics signature study in hepatocellular carcinoma revealed that immune cell function, not immune cell infiltration in the TME, determined immunotherapeutic response [50]. Due to the heterogeneity of the TME, a majority of patients are resistant to $\alpha-\mathrm{PD}-1 / \mathrm{PD}-\mathrm{L} 1 \mathrm{mon}-$ otherapy [51-53]. For the non-responders, the PD-1/ PD-L1 pathway is not the predominant immune defect in the TME, and blocking PD-1/PD-L1 is insufficient to break immune tolerance and trigger immune killing. Hereto, accumulating combination strategies are developed to improve $\alpha$-PD-1/PD-L1 efficacy and alleviate treatment resistance by enhancing immunogenic cancer cell death, promoting antigen presentation, and rescuing other dysfunctional effectors [54-57].

In the TME, STING pathway plays a vital role in crosspresentation and priming. The development of STING agonists has been a hot issue in cancer therapeutics. DMXAA is the first agent activating murine STING pathway but failed in phase III clinical study [58]. Further investigation showed that the interaction between human STING and DMXAA was weak [59]. Besides, other traditional STING agonists such as cGAMP also have some drawbacks, such as low stability and poor transmembrane capability. Although some novel STING agonists have been developed in the past decade [32, 60], $\mathrm{Mn}^{2+}$ has a significant advantage in manufacturing cost and well-studied toxicity. As a natural and easily available STING agonist, $\mathrm{Mn}^{2+}$ might be a promising adjuvant drug of immunotherapy.

Manganese is a trace element participating in multiple physiological activities, including reproduction, development, energy metabolism, and antioxidant defenses [61]. Manganese also regulates innate immunity by sensitizing STING pathway [33]. The concentration of manganese in mammalian tissue ranges from 0.3 to $2.9 \mu \mathrm{g} / \mathrm{g}$ wet

\footnotetext{
(See figure on next page.)

Fig. 8 RNA-seq assay to investigate the immune profile of the B16 tumors. a The heatmap presenting the relative expression levels of differentially expressed genes ( $n=4$ biological replicates). $\mathbf{b}-\mathbf{e}$ Gene set enrichment analysis (GSEA) showing the significantly enriched biological processes in $\mathrm{Mn}^{2+}$ plus YM101-treated tumors, relative to YM101-treated tumors. The biological processes including activation of immune response, activation of innate immune response, positive regulation of adaptive immune response, IFN-I production, IFN-I signaling pathway, response to IFN-I, T cell activation, NK activation, B cell activation, macrophage activation, myeloid dendritic cell activation, cell killing, T cell mediated cytotoxicity, NK mediated cytotoxicity, and antigen processing and presentation were significantly enriched in the combination group. $\mathbf{f}-\mathbf{k}$ The scores of signatures of T cell, NK, dendritic cell (DC), macrophage, IFN-a response, and IFN- $\gamma$ response. ${ }^{*} p<0.05,{ }^{* *} p<0.01,{ }^{* * *} p<0.001$, and ${ }^{* * *} p<0.0001$ denote the significant difference relative to combination treatment
} 


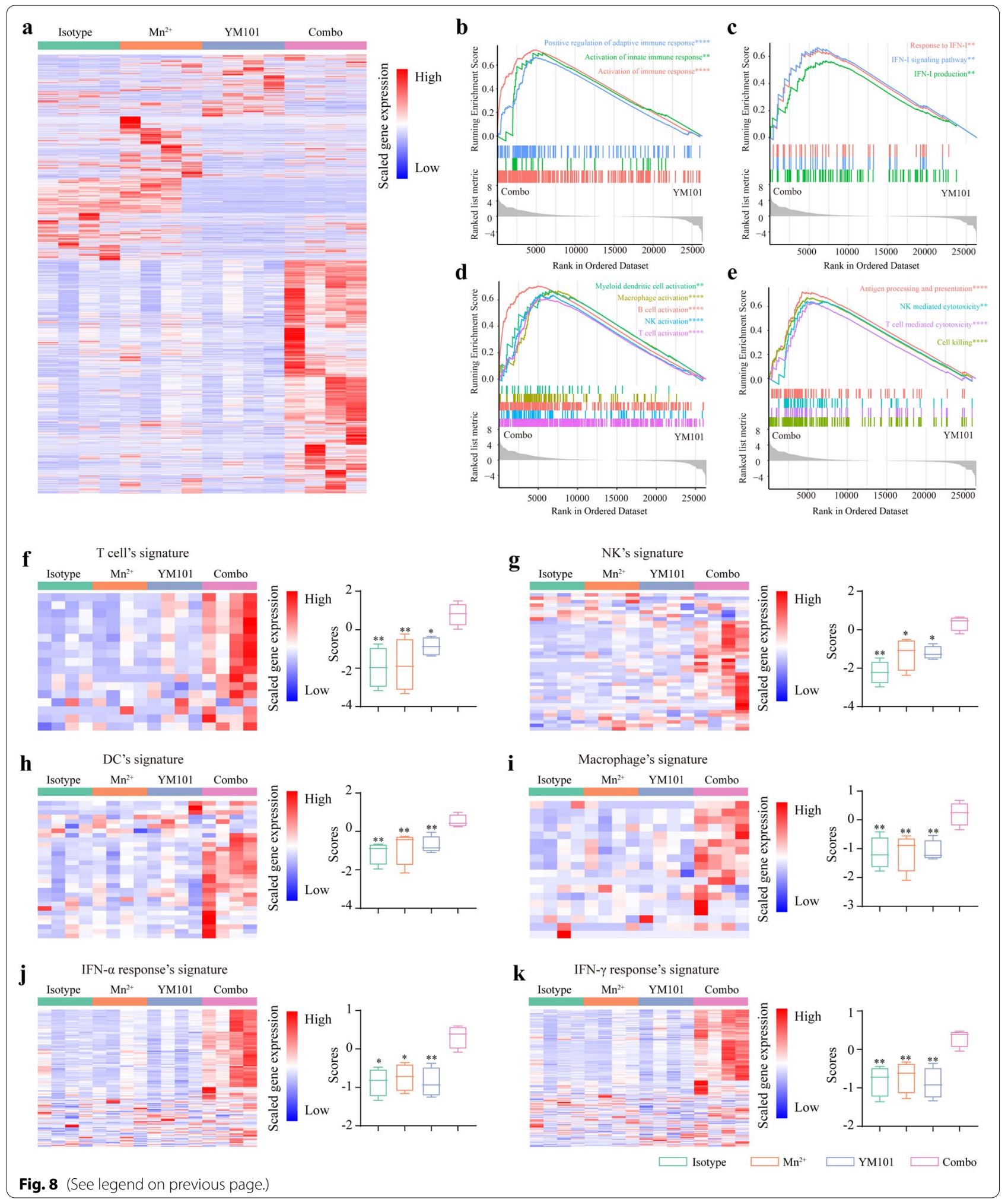


a

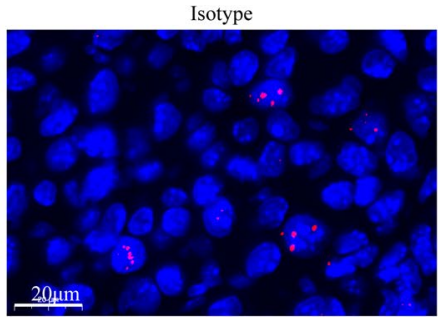

YM101
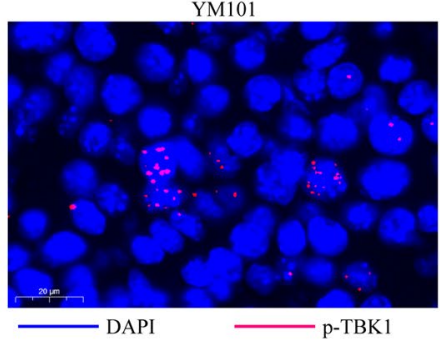

b

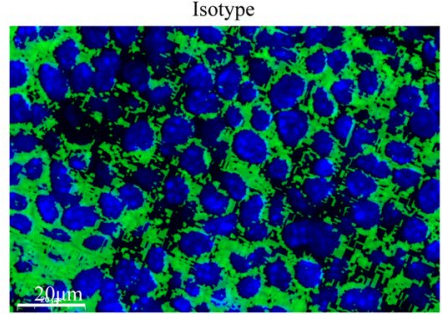

YM101
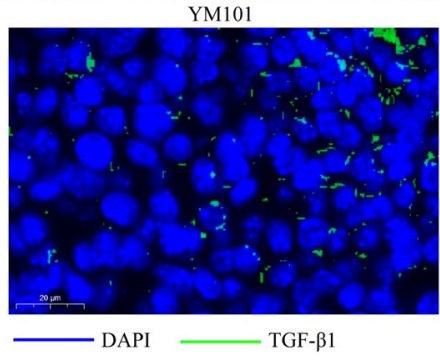

c

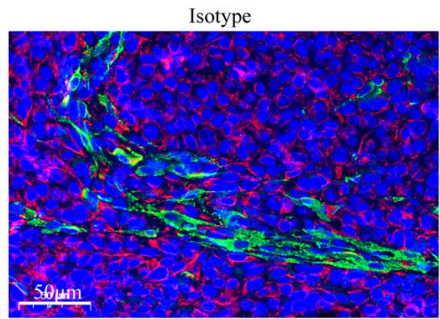

YM101

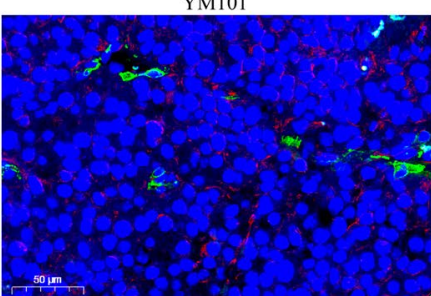

DAPI

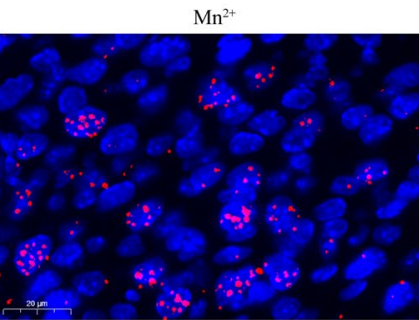

Combo

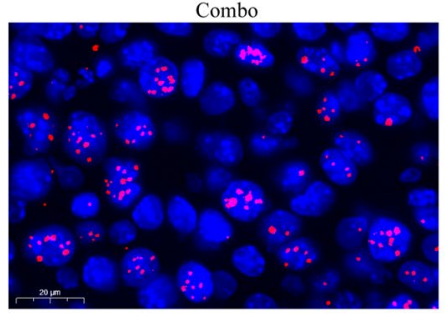

$\mathrm{Mn}^{2+}$

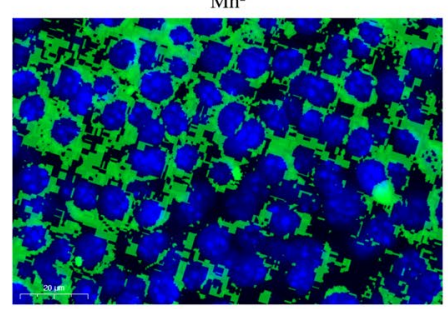

Combo
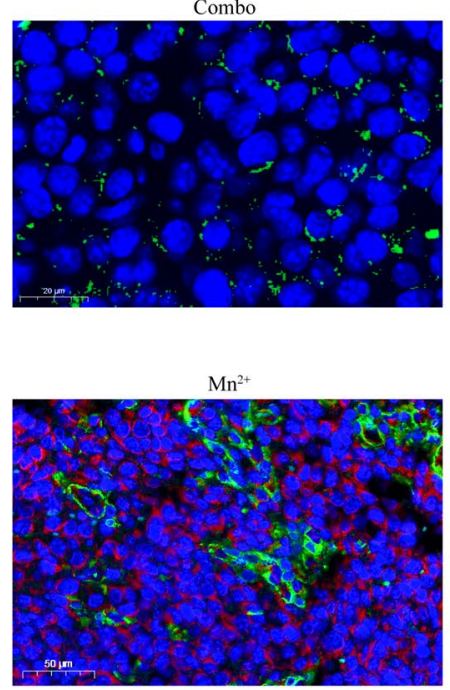

Combo

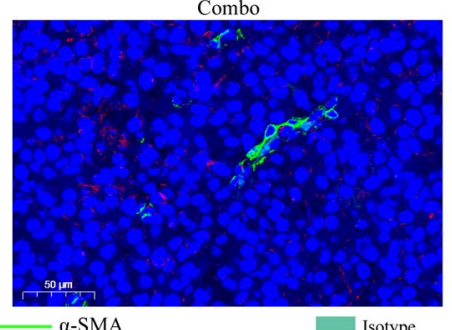

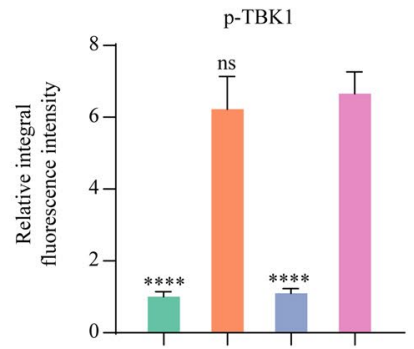
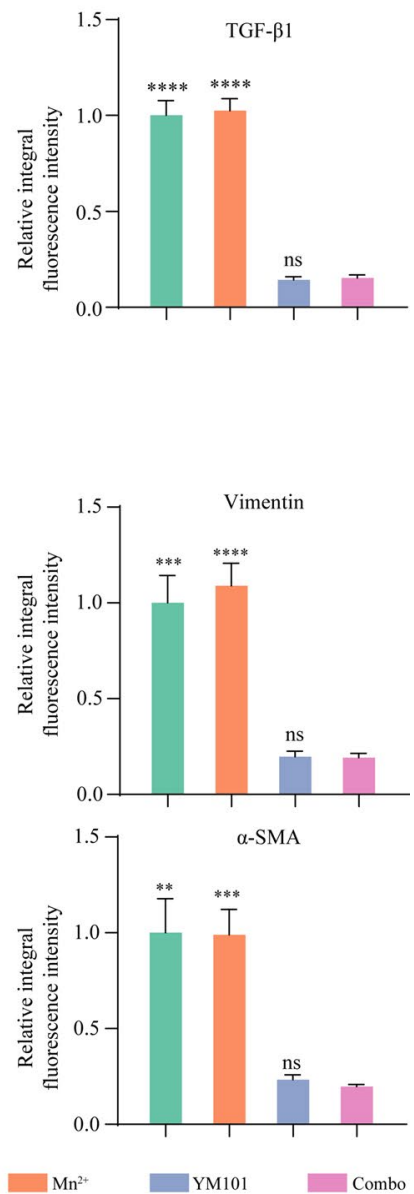

Fig. 9 Immunofluorescent staining assays to measure the status of STING pathway, TGF- $\beta$ signal, and epithelial-mesenchymal transition in the B16 model. The representative images of $\mathbf{a}$ a-p-TBK1 staining, $\mathbf{b}$ a-TGF- $\beta 1$ staining, (c) a-SMA and a-Vimentin staining ( $n=5$ biological replicates). ${ }^{*} p<0.05,{ }^{* *} p<0.01,{ }^{* * *} p<0.001$, and ${ }^{* * *} p<0.0001$ denote the significant difference relative to combination treatment 


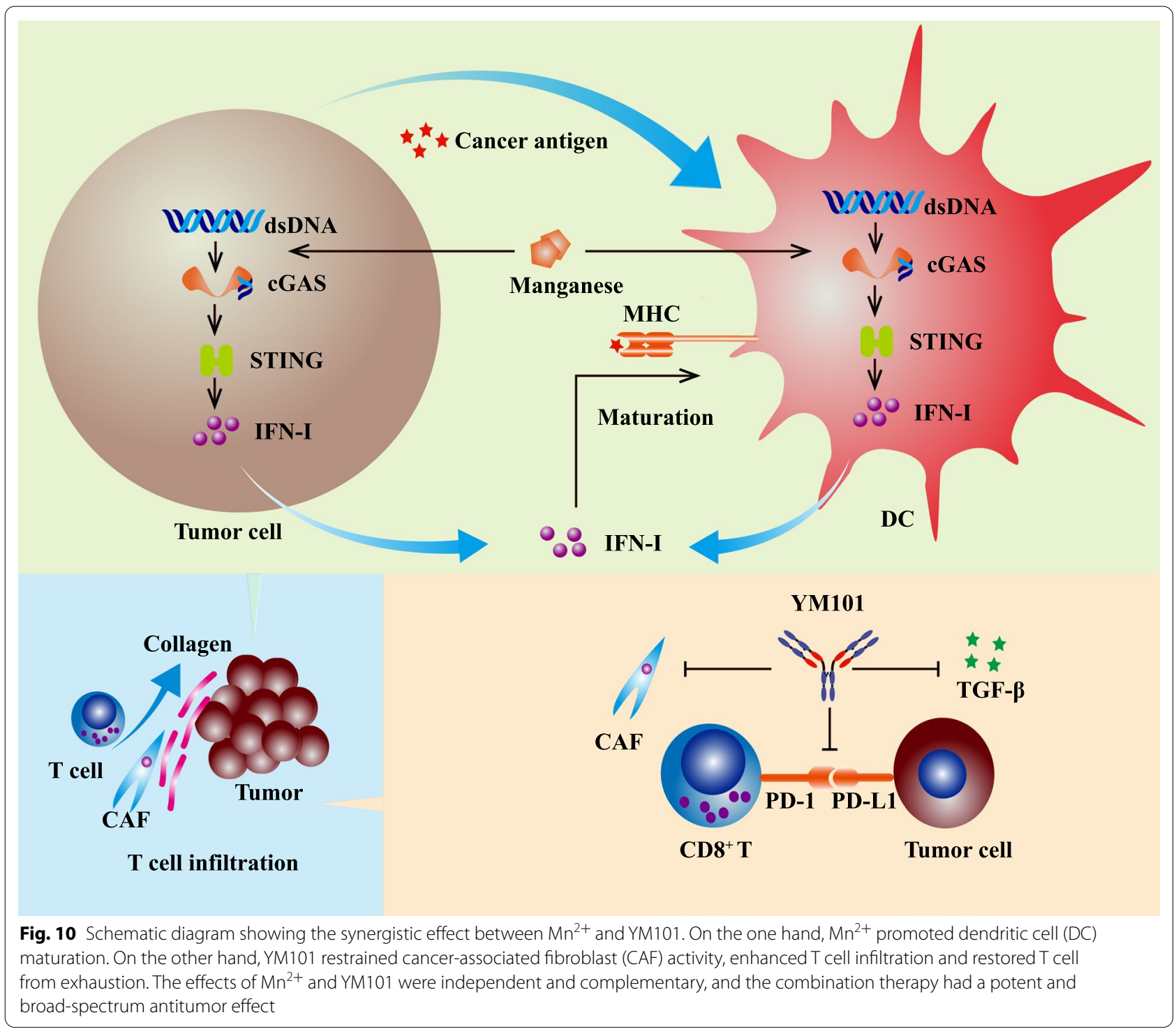

tissue [62]. According to the recommendations of Dietary Reference Intake, $2 \mathrm{mg} /$ day manganese is an adequate intake for adults, and the tolerable upper intake level is 9-11 mg/day [61]. The gastrointestinal tract negatively regulates the absorption of manganese: High manganese intake decreases intestinal absorption but increases biliary and pancreatic excretion [63]. The manganese turnover is rapid, and the mean retention is 10 days after digestion [64]. It has been reported that $2 \mu \mathrm{M} \mathrm{Mn}{ }^{2+}$ endowed THP1 (human monocyte line) with antivirus capability in vitro [33]. In the present study, we found $\mathrm{Mn}^{2+}$ treatment promoted DC maturation and antigen presentation capability. Besides, it was reported $5 \mathrm{mg} / \mathrm{kg}$ $\mathrm{Mn}^{2+}$ treatment enhanced the efficacy of $\alpha-\mathrm{PD}-1 / \mathrm{PD}-\mathrm{L} 1$ in murine tumor models [36]. Additionally, another preclinical study showed that $\mathrm{Mn}^{2+}$-based nanoparticles boosted antitumor immunity by activating STING pathway [65]. Notably, the results of a phase I clinical study showed that $\mathrm{Mn}^{2+}$ intranasal administration or inhalation augmented the effect of chemoimmunotherapy, even in patients previously failing to chemotherapy combined with $\alpha-\mathrm{PD}-1$ treatment [36]. Importantly, $\mathrm{Mn}^{2+}$ treatment had high biosafety, and no manganese overdoseassociated toxicity was observed at follow-up [36].

In this study, we investigated the efficacy of $\mathrm{Mn}^{2+}$ plus $\alpha$-TGF- $\beta$ /PD-L1 BsAb YM101, which simultaneously activated STING pathway and suppressed TGF- $\beta$ and PD-1/PD-L1 signals (Fig. 10). This novel cocktail strategy had a broader antitumor spectrum and more potent antitumor activity than YM101 monotherapy. Specifically, 
although YM101 effectively retarded tumor growth in some immune-excluded tumor models, its antitumor effect was limited in the immune-desert tumor model. The combination therapy dramatically boosted the efficacy of YM101, especially in the poorly immunogenic tumor. The flow cytometry and RNA-seq data showed that the combination treatment significantly upregulated the densities and functions of tumor-infiltrating $\mathrm{CD} 8^{+}$ $\mathrm{T}$ and NK cells. Besides, a series of innate and adaptive immunity-related biological processes were markedly enriched after the combination therapy. Our results indicated that this combination strategy successfully overcame the weak immunogenicity-caused treatment resistance and effectively reinvigorated adaptive antitumor immunity by stimulating innate immunity.

It was reported that $\mathrm{Mn}^{2+}$ plus $\alpha$-PD-1/PD-L1 had better antitumor efficacy than $\alpha$-PD-1/PD-L1 monotherapy [36]. In the present study, we confirmed this synergistic effect. However, in immune-excluded tumor model, the antitumor effect of $\mathrm{Mn}^{2+}$ plus $\alpha$-PD-1/PD-L1 was modest, significantly weaker than that of $\mathrm{Mn}^{2+}$ plus YM101. Our previous work showed that in EMT-6 model, hyperactive TGF- $\beta$ signaling in the TME was related to increased collagen deposition and hampered $\mathrm{T}$ cell infiltration [27]. Blocking TGF- $\beta$ promoted T cell infiltration and improved the effect of $\alpha$-PD-1/PD-L1 [27]. Consistently, $\mathrm{Mn}^{2+}$ plus YM101 promoted T cell penetration into tumors. This shift from immune-excluded to immune-inflamed might contribute to the enhanced antitumor effect of $\mathrm{Mn}^{2+}$ plus YM101 therapy in high TGF- $\beta$ models.

The cocktail strategy of $\mathrm{Mn}^{2+}$ plus YM101 is a potent and broad-spectrum antitumor immunotherapy. In the real world, combination therapy means a higher risk of immune-related adverse events. Although we had not observed treatment-associated toxicity in murine tumor models, further explorations are needed to confirm the safety and efficacy of this combination therapy.

\section{Conclusion}

In this study, we developed a novel combination therapy of $\mathrm{Mn}^{2+}$ and YM101, which simultaneously boosted innate and adaptive immunity. This novel cocktail strategy had a superior antitumor effect to YM101 monotherapy and $\mathrm{Mn}^{2+}$ plus $\alpha$-PD-1/PD-L1 therapy. Further investigation indicated that $\mathrm{Mn}^{2+}$ plus YM101 treatment promoted the transformation from non-inflamed to immune-inflamed tumor: restraining CAF activity and collagen production, increasing the infiltration of effector cells, enhancing the tumor-killing activities of $\mathrm{T}$ cells and NKs, strengthening the antigen presentation of APCs, and upregulating the ratio of memory T cells. Generally, this combination therapy exhibited a broad antitumor spectrum even in immune-excluded and immune-desert tumors. We believed this $\mathrm{Mn}^{2+}$-based combination therapy could greatly relieve $\alpha-\mathrm{PD}-1 /$ PD-L1 resistance and become a universal immunotherapy strategy across all three phenotypes of tumors.

\section{Abbreviations}

BMDC: Bone marrow-derived dendritic cell; BsAb: Bispecific antibody; CAF: Carcinoma-associated fibroblast; CFSE: Carboxyfluorescein diacetate sUccinimidyl ester; DC: Dendritic cells; DEG: Differentially expressed gene; EMT: Epithelial-mesenchymal transition; ELISA: Enzyme-linked immunosorbent assay; GSEA: Gene set enrichment analysis; IFN: Interferon; MHC: Major histocompatibility complex; MLR: Mixed lymphocyte reaction; MoDC: Monocytederived dendritic cell; PBMC: Peripheral blood mononuclear cell; PD-1: Programmed cell death protein 1 ; TGF- $\beta$ : Transforming growth factor-beta; TIL: Tumor-infiltrating lymphocytes; TME: Tumor microenvironment; Treg: Regulatory T; STING: Stimulator of interferon genes.

\section{Supplementary Information}

The online version contains supplementary material available at https://doi. org/10.1186/s13045-021-01155-6.

Additional file 1. Supplementary table and figures.

Additional file 2. RNA-seq profile.

Acknowledgements

Not applicable.

Authors' contributions

MY conducted the experiments and drafted the manuscript. MN, JZ, SL, SZ, YY, NL, PZ, and QC participated in the analysis and interpretation of data. KW designed the work. All authors read and approved the final manuscript.

Funding

This work was supported by the National Natural Science Foundation of China (Nos. 82073370 and 81874120 ).

Availability of data and materials

The dataset generated during the current study is available from the corresponding author on reasonable request.

\section{Declarations}

Ethics approval and consent to participate

The animal operations in this study were evaluated and approved by the Institutional Animal Care and Use Committee of Tongji Hospital of Huazhong University of Sciences and Technology.

\section{Consent for publication}

Not applicable.

\section{Competing interests}

JZ, YY, and PZ were employees of Wuhan YZY Biopharma Co., Ltd.

\section{Author details}

${ }^{1}$ Department of Oncology, Tongji Hospital of Tongji Medical College, Huazhong University of Science and Technology, 1095 Jiefang Avenue, Wuhan 430030, People's Republic of China. ${ }^{2}$ Wuhan YZY Biopharma Co., Ltd, Biolake, C2-1, No.666 Gaoxin Road, Wuhan 430075, People's Republic of China. ${ }^{3}$ Department of Medical Oncology, The Affiliated Cancer Hospital of Zhengzhou University \& Henan Cancer Hospital, Zhengzhou 450008, People's Republic of China. 
Received: 22 June 2021 Accepted: 30 August 2021

Published online: 15 September 2021

\section{References}

1. Chen DS, Mellman I. Oncology meets immunology: the cancer-immunity cycle. Immunity. 2013;39:1-10.

2. Pio R, Ajona D, Ortiz-Espinosa S, Mantovani A, Lambris JD. Complementing the cancer-immunity cycle. Front Immunol. 2019;10:774.

3. Yi M, Qin S, Zhao W, Yu S, Chu Q, Wu K. The role of neoantigen in immune checkpoint blockade therapy. Exp Hematol Oncol. 2018;7:28.

4. Zitvogel L, Tesniere A, Kroemer G. Cancer despite immunosurveillance: immunoselection and immunosubversion. Nat Rev Immunol. 2006:6:715-27.

5. Chen DS, Mellman I. Elements of cancer immunity and the cancerimmune set point. Nature. 2017:541:321-30.

6. Huang X, Zhang X, Li E, Zhang G, Wang X, Tang T, et al. VISTA: an immune regulatory protein checking tumor and immune cells in cancer immunotherapy. J Hematol Oncol. 2020;13:83.

7. Eladl E, Tremblay-LeMay R, Rastgoo N, Musani R, Chen W, Liu A, et al. Role of CD47 in hematological malignancies. J Hematol Oncol. 2020;13:96.

8. Qin S, Xu L, Yi M, Yu S, Wu K, LuO S. Novel immune checkpoint targets: moving beyond PD-1 and CTLA-4. Mol Cancer. 2019;18:155.

9. Yi M, Xu L, Jiao Y, Luo S, Li A, Wu K. The role of cancer-derived microRNAs in cancer immune escape. J Hematol Oncol. 2020;13:25.

10. Chen L, Han X. Anti-PD-1/PD-L1 therapy of human cancer: past, present, and future. J Clin Invest. 2015;125:3384-91.

11. Dong H, Strome SE, Salomao DR, Tamura H, Hirano F, Flies DB, et al. Tumor-associated B7-H1 promotes T-cell apoptosis: a potential mechanism of immune evasion. Nat Med. 2002;8:793-800.

12. Chen $Y$, Wang $Y$, Luo $H$, Meng $X$, Zhu W, Wang $D$, et al. The frequency and inter-relationship of PD-L1 expression and tumour mutational burden across multiple types of advanced solid tumours in China. Exp Hematol Oncol. 2020:9:17.

13. Zou W, Wolchok JD, Chen L. PD-L1 (B7-H1) and PD-1 pathway blockade for cancer therapy: Mechanisms, response biomarkers, and combinations. Sci Transl Med. 2016;8:328rv4.

14. Herbst RS, Giaccone G, de Marinis F, Reinmuth N, Vergnenegre A, Barrios $\mathrm{CH}$, et al. Atezolizumab for first-line treatment of PD-L1-selected patients with NSCLC. N Engl J Med. 2020;383:1328-39.

15. Motzer RJ, Penkov K, Haanen J, Rini B, Albiges L, Campbell MT, et al. Avelumab plus axitinib versus sunitinib for advanced renal-cell carcinoma. $N$ Engl J Med. 2019;380:1103-15.

16. Salik B, Smyth MJ, Nakamura K. Targeting immune checkpoints in hematological malignancies. J Hematol Oncol. 2020;13:111.

17. Chen R, Manochakian R, James L, Azzouqa AG, Shi H, Zhang Y, et al. Emerging therapeutic agents for advanced non-small cell lung cancer. J Hematol Oncol. 2020;13:58.

18. Zhu XD, Sun HC. Emerging agents and regimens for hepatocellular carcinoma. J Hematol Oncol. 2019;12:110.

19. Robert C, Schachter J, Long GV, Arance A, Grob JJ, Mortier L, et al. Pembrolizumab versus Ipilimumab in advanced melanoma. N Engl J Med. 2015;372:2521-32.

20. Tang B, Yan X, Sheng X, Si L, Cui C, Kong Y, et al. Safety and clinical activity with an anti-PD-1 antibody JS001 in advanced melanoma or urologic cancer patients. J Hematol Oncol. 2019;12:7.

21. Qiu Z, Chen Z, Zhang C, Zhong W. Achievements and futures of immune checkpoint inhibitors in non-small cell lung cancer. Exp Hematol Oncol. 2019;8:19.

22. Yi M, Jiao D, Xu H, Liu Q, Zhao W, Han X, et al. Biomarkers for predicting efficacy of PD-1/PD-L1 inhibitors. Mol Cancer. 2018;17:129.

23. Niu M, Yi M, Li N, Luo S, Wu K. Predictive biomarkers of anti-PD-1/PD-L1 therapy in NSCLC. Exp Hematol Oncol. 2021;10:18.

24. Sanmamed MF, Chen L. A paradigm shift in cancer immunotherapy: from enhancement to normalization. Cell. 2018:175:313-26.

25. Batlle E, Massagué J. Transforming growth factor- $\beta$ signaling in immunity and cancer. Immunity. 2019;50:924-40.
26. Bai X, Yi M, Jiao Y, Chu Q, Wu K. Blocking TGF- $\beta$ signaling to enhance the efficacy of immune checkpoint inhibitor. Onco Targets Ther. 2019:12:9527-38.

27. Yi M, Zhang J, Li A, Niu M, Yan Y, Jiao Y, et al. The construction, expression, and enhanced anti-tumor activity of YM101: a bispecific antibody simultaneously targeting TGF- $\beta$ and PD-L1. J Hematol Oncol. $2021 ; 14: 27$

28. Smyth MJ, Ngiow SF, Ribas A, Teng MW. Combination cancer immunotherapies tailored to the tumour microenvironment. Nat Rev Clin Oncol. 2016;13:143-58.

29. Jiang M, Chen P, Wang L, Li W, Chen B, Liu Y, et al. CGAS-STING, an important pathway in cancer immunotherapy. J Hematol Oncol. 2020;13:81.

30. Li A, Yi M, Qin S, Song Y, Chu Q, Wu K. Activating cGAS-STING pathway for the optimal effect of cancer immunotherapy. J Hematol Oncol. 2019;12:35

31. Ghaffari A, Peterson N, Khalaj K, Vitkin N, Robinson A, Francis JA, et al. STING agonist therapy in combination with PD-1 immune checkpoint blockade enhances response to carboplatin chemotherapy in high-grade serous ovarian cancer. Br J Cancer. 2018;119:440-9

32. Pan BS, Perera SA, Piesvaux JA, Presland JP, Schroeder GK, Cumming JN, et al. An orally available non-nucleotide STING agonist with antitumor activity. Science. 2020;369.

33. Wang C, Guan Y, Lv M, Zhang R, Guo Z, Wei X, et al. Manganese increases the sensitivity of the CGAS-STING pathway for double-stranded DNA and is required for the host defense against DNA viruses. Immunity. 2018:48:675-87.e7.

34. Zhang R, Wang C, Guan Y, Wei X, Sha M, Yi M, et al. Manganese salts function as potent adjuvants. Cell Mol Immunol. 2021;18:1222-34.

35. Wang C, Zhang R, Wei X, Lv M, Jiang Z. Metalloimmunology: the metal ion-controlled immunity. Adv Immunol. 2020;145:187-241.

36. Lv M, Chen M, Zhang R, Zhang W, Wang C, Zhang Y, et al. Manganese is critical for antitumor immune responses via cGAS-STING and improves the efficacy of clinical immunotherapy. Cell Res. 2020:30:966-79.

37. Yu S, Zhang J, Yan Y, Yao X, Fang L, Xiong H, et al. A novel asymmetrical anti-HER2/CD3 bispecific antibody exhibits potent cytotoxicity for HER2positive tumor cells. J Exp Clin Cancer Res. 2019;38:355.

38. Liu Q, Li A, Yu S, Qin S, Han N, Pestell RG, et al. DACH1 antagonizes CXCL8 to repress tumorigenesis of lung adenocarcinoma and improve prognosis. J Hematol Oncol. 2018;11:53.

39. Wang G, Achim CL, Hamilton RL, Wiley CA, Soontornniyomkij V. Tyramide signal amplification method in multiple-label immunofluorescence confocal microscopy. Methods. 1999:18:459-64.

40. Yu G, Wang LG, Han Y, He QY. clusterProfiler: an R package for comparing biological themes among gene clusters. OMICS. 2012;16:284-7.

41. Wu D, Lim E, Vaillant F, Asselin-Labat ML, Visvader JE, Smyth GK. ROAST: rotation gene set tests for complex microarray experiments. Bioinformatics. 2010;26:2176-82.

42. Kadoshima-Yamaoka K, Murakawa M, Goto M, Tanaka Y, Inoue H, Murafuji $\mathrm{H}$, et al. Effect of phosphodiesterase 7 inhibitor ASB16165 on development and function of cytotoxic T lymphocyte. Int Immunopharmacol. 2009:9:97-102

43. Mariathasan S, Turley SJ, Nickles D, Castiglioni A, Yuen K, Wang Y, et al. TGF $\beta$ attenuates tumour response to PD-L1 blockade by contributing to exclusion of T cells. Nature. 2018;554:544-8.

44. Holmgaard RB, Schaer DA, LiY, Castaneda SP, Murphy MY, Xu X, et al. Targeting the TGF $\beta$ pathway with galunisertib, a TGF $\beta$ RI small molecule inhibitor, promotes anti-tumor immunity leading to durable, complete responses, as monotherapy and in combination with checkpoint blockade. J Immunother Cancer. 2018;6:47.

45. Qin W, Zou J, Huang Y, Liu C, Kang Y, Han H, et al. Pirfenidone facilitates immune infiltration and enhances the antitumor efficacy of PD-L1 blockade in mice. Oncoimmunology. 2020;9:1824631.

46. Lan Y, Zhang D, Xu C, Hance KW, Marelli B, Qi J, et al. Enhanced preclinical antitumor activity of M7824, a bifunctional fusion protein simultaneously targeting PD-L1 and TGF- $\beta$. Sci Transl Med. 2018;10.

47. Tauriello DVF, Palomo-Ponce S, Stork D, Berenguer-Llergo A, BadiaRamentol J, Iglesias $M$, et al. TGF $\beta$ drives immune evasion in genetically reconstituted colon cancer metastasis. Nature 2018:554:538-43. 
48. Yi M, Jiao D, Qin S, Chu Q, Wu K, Li A. Synergistic effect of immune checkpoint blockade and anti-angiogenesis in cancer treatment. Mol Cancer. 2019;18:60.

49. Qin S, Li A, Yi M, Yu S, Zhang M, Wu K. Recent advances on anti-angiogenesis receptor tyrosine kinase inhibitors in cancer therapy. J Hematol Oncol. 2019;12:27.

50. Liu F, Qin L, Liao Z, Song J, Yuan C, Liu Y, et al. Microenvironment characterization and multi-omics signatures related to prognosis and immunotherapy response of hepatocellular carcinoma. Exp Hematol Oncol. 2020;9:10

51. Yap TA, Parkes EE, Peng W, Moyers JT, Curran MA, Tawbi HA. Development of Immunotherapy Combination Strategies in Cancer. Cancer Discov. 2021:11:1368-97.

52. Verma $V$, Sharma $G$, Singh A. Immunotherapy in extensive small cell lung cancer. Exp Hematol Oncol. 2019;8:5.

53. Yuan X, Yi M, Zhang W, Xu L, Chu Q, Luo S, et al. The biology of combination immunotherapy in recurrent metastatic head and neck cancer. Int $J$ Biochem Cell Biol. 2021;136:106002.

54. Li A, Yi M, Qin S, Chu Q, Luo S, Wu K. Prospects for combining immune checkpoint blockade with PARP inhibition. J Hematol Oncol. 2019:12:98.

55. Zhao S, Ren S, Jiang T, Zhu B, Li X, Zhao C, et al. Low-dose apatinib optimizes tumor microenvironment and potentiates antitumor effect of PD-1/PD-L1 blockade in lung cancer. Cancer Immunol Res. 2019:7:630-43.

56. Hung AL, Maxwell R, Theodros D, Belcaid Z, Mathios D, Luksik AS, et al. TIGIT and PD-1 dual checkpoint blockade enhances antitumor immunity and survival in GBM. Oncoimmunology. 2018;7:e1466769.

57. Wu K, Yi M, Qin S, Chu Q, Zheng X, Wu K. The efficacy and safety of combination of PD-1 and CTLA-4 inhibitors: a meta-analysis. Exp Hematol Oncol. 2019;8:26.
58. Ding C, Song Z, Shen A, Chen T, Zhang A. Small molecules targeting the innate immune cGAS-STING-TBK1 signaling pathway. Acta Pharm Sin B. 2020;10:2272-98.

59. Conlon J, Burdette DL, Sharma S, Bhat N, Thompson M, Jiang Z, et al. Mouse, but not human STING, binds and signals in response to the vascular disrupting agent 5,6-dimethylxanthenone-4-acetic acid. J Immunol. 2013;190:5216-25.

60. Ramanjulu JM, Pesiridis GS, Yang J, Concha N, Singhaus R, Zhang SY, et al. Design of amidobenzimidazole STING receptor agonists with systemic activity. Nature. 2018;564:439-43.

61. Horning KJ, Caito SW, Tipps KG, Bowman AB, Aschner M. Manganese is essential for neuronal health. Annu Rev Nutr. 2015;35:71-108.

62. Aschner $\mathrm{L}$, Aschner M. Nutritional aspects of manganese homeostasis. Mol Aspects Med. 2005;26:353-62.

63. Andersen ME, Gearhart JM, Clewell HJ 3rd. Pharmacokinetic data needs to support risk assessments for inhaled and ingested manganese. Neurotoxicology. 1999;20:161-71.

64. Davidsson L, Cederblad A, Lönnerdal B, Sandström B. Manganese absorption from human milk, cow's milk, and infant formulas in humans. Am J Dis Child. 1989;143:823-7.

65. Hou L, Tian C, Yan Y, Zhang L, Zhang H, Zhang Z. Manganese-based nanoactivator optimizes cancer immunotherapy via enhancing innate immunity. ACS Nano. 2020;14:3927-40.

\section{Publisher's Note}

Springer Nature remains neutral with regard to jurisdictional claims in published maps and institutional affiliations.
Ready to submit your research? Choose BMC and benefit from:

- fast, convenient online submission

- thorough peer review by experienced researchers in your field

- rapid publication on acceptance

- support for research data, including large and complex data types

- gold Open Access which fosters wider collaboration and increased citations

- maximum visibility for your research: over $100 \mathrm{M}$ website views per year

At BMC, research is always in progress.

Learn more biomedcentral.com/submissions 